\title{
A Duplicated Copy of the Meiotic Gene ZIP4 Preserves up to $50 \%$ Pollen Viability and Grain Number in Polyploid Wheat
}

\author{
Abdul Kader Alabdullah D, Graham Moore* and Azahara C. Martín \\ Crop Genetics Department, John Innes Centre, Colney, Norwich NR4 7UH, UK; \\ Abdul-Kader.Alabdullah@jic.ac.uk (A.K.A.); Azahara-C.Martin@jic.ac.uk (A.C.M.) \\ * Correspondence: graham.moore@jic.ac.uk
}

Citation: Alabdullah, A.K.; Moore, G.; Martín, A.C. A Duplicated Copy of the Meiotic Gene ZIP4 Preserves up to $50 \%$ Pollen Viability and Grain Number in Polyploid Wheat. Biology 2021, 10, 290. https://doi.org/ 10.3390/biology10040290

Academic Editors: Pierre Devaux and Pierre Sourdille

Received: 18 March 2021

Accepted: 31 March 2021

Published: 2 April 2021

Publisher's Note: MDPI stays neutral with regard to jurisdictional claims in published maps and institutional affiliations.

Copyright: (c) 2021 by the authors. Licensee MDPI, Basel, Switzerland. This article is an open access article distributed under the terms and conditions of the Creative Commons Attribution (CC BY) license (https:/ / creativecommons.org/licenses/by/ $4.0 /)$.
Simple Summary: On wheat polyploidisation, the major meiotic gene ZIP4, duplicated and diverged, such that tetraploid and hexaploid wheat each carry three and four copies of ZIP4, respectively. Surprisingly, this study demonstrates that, in hexaploid wheat, despite the presence of the other three ZIP4 copies, the duplicated ZIP4 copy is required to prevent major abnormalities during meiosis. Although there is greater disruption of subsequent male rather than female fertility, the duplicated ZIP4 copy preserves up to $50 \%$ of the grain number. High wheat fertility is important since it is consumed by over 4.5 billion people on the planet, of whom 2.5 billion are dependent on it. This study highlights the potentially extraordinary value of the wheat ZIP4 duplication, mandating further studies to unravel the complexity of the ZIP4 phenotype in this global crop.

Abstract: Although most flowering plants are polyploid, little is known of how the meiotic process evolves after polyploidisation to stabilise and preserve fertility. On wheat polyploidisation, the major meiotic gene ZIP4 on chromosome 3B duplicated onto 5B and diverged (TaZIP4-B2). TaZIP4$B 2$ was recently shown to promote homologous pairing, synapsis and crossover, and suppress homoeologous crossover. We therefore suspected that these meiotic stabilising effects could be important for preserving wheat fertility. A CRISPR Tazip4-B2 mutant was exploited to assess the contribution of the $5 \mathrm{~B}$ duplicated ZIP4 copy in maintaining pollen viability and grain setting. Analysis demonstrated abnormalities in 56\% of meiocytes in the Tazip4-B2 mutant, with micronuclei in 50\% of tetrads, reduced size in $48 \%$ of pollen grains and a near $50 \%$ reduction in grain number. Further studies showed that most of the reduced grain number occurred when Tazip4-B2 mutant plants were pollinated with the less viable Tazip4-B2 mutant pollen rather than with wild type pollen, suggesting that the stabilising effect of TaZIP4-B2 on meiosis has a greater consequence in subsequent male, rather than female gametogenesis. These studies reveal the extraordinary value of the wheat chromosome 5B TaZIP4-B2 duplication to agriculture and human nutrition. Future studies should further investigate the role of TaZIP4-B2 on female fertility and assess whether different TaZIP4-B2 alleles exhibit variable effects on meiotic stabilisation and/or resistance to temperature change.

Keywords: wheat; polyploidy; meiosis; ZIP4; Ph1 gene; pollen analysis; fertility

\section{Introduction}

Polyploidy occurs in a wide range of species, including fish, flatworms, shrimp, amphibians, flowering plants, wine and brewing yeast [1-4]. The molecular mechanisms responsible for meiotic polyploidisation and diploid behaviour are important for ensuring correct chromosome segregation of multiple related chromosomes, production of balanced gametes and hence preservation of fertility. It is surprising that these mechanisms have not been more widely investigated, given their potentially enormous value to humankind [4].

Polyploids can either arise via multiplication of a basic set of chromosomes (termed an autopolyploid, such as potato) or by combining related but not completely identical genomes (termed an allopolyploid, such as hexaploid (bread) wheat). Plant polyploidisation is often associated with extensive chromosomal rearrangements and changes in 
gene content and expression [3,5-7]. Yet, analysis of the recently sequenced hexaploid wheat (Triticum aestivum L.) genome and wheat RNA seq datasets from over 1000 tissues (including meiocytes), did not reveal extensive gene loss or changes in expression between related (homoeologous) chromosomes following polyploidisation [8]. Even meiotic genes do not appear to have suffered gene loss, exhibiting mostly balanced expression between copies on related chromosomes (homoeologues) [9]. Thus, hexaploid wheat appears to have suffered less extensive rearrangement.

It was previously accepted that a locus arising on chromosome $5 \mathrm{~B}$ during wheat polyploidisation, was responsible for stabilising the wheat genome during meiosis, hence maintaining fertility. This was based on earlier cytogenetic studies of hexaploid wheat lines lacking the whole of chromosome $5 \mathrm{~B}$, which when crossed with wild relatives, exhibited homoeologous crossover between wheat and wild relative chromosomes at metaphase I in the resulting hybrids $[10,11]$. It was unclear at the time which and how many of these genes needed to be lost to produce the phenotype. However, it was recognised from these early studies that suppression of homoeologous crossover was important for stabilising the wheat genome and maintaining its fertility. In 1971, a study coined the term 'pairing homoeologous' (Ph1) for this 'critical locus' on 5B, responsible for suppressing the homoeologous crossover observed in wheat-wild relative hybrids [12]. Loss of Ph1 (or of the whole $5 \mathrm{~B}$ chromosome, as in these studies) allowed homoeologous crossover to take place. The term 'pairing' was used synonymously with crossover observed at metaphase I at this time. 'Ph1' became the accepted term to describe the locus responsible for the homoeologous crossover suppression phenotype.

Sears [13] identified a mutant (named ph1b) carrying a deletion of part of chromosome $5 B$ (now known to be $59.3 \mathrm{Mb}$ in size, encompassing some 1187 genes [14]). When the Sears ph1b mutant was crossed with wild relatives to form hybrids, crossover between homoeologues was subsequently observed during meiosis in these hybrids. Later, Roberts et al. [15] observed that mutants carrying deletions in the long arm of chromosome $5 \mathrm{~B}$ could be separated into 2 groups by scoring the configurations at metaphase I during meiosis in the mutants. Univalents, rod bivalents and multivalents were present in over $50 \%$ of meiocytes at metaphase I in the Sears $p h 1 b$ mutant (and also some of the 5B deletion mutants), while the wild type (WT) wheat and the remaining 5B deletion mutants exhibited mainly bivalents at metaphase I in all their meiocytes. Thus, the presence of meiotic abnormalities in over $50 \%$ of meiocytes could separate the 5B deletion mutants into two distinct groups [15]. Presence of multivalents suggested that the initial alignment of chromosomes (now termed 'pairing') and intimate pairing (now termed 'synapsis') of chromosomes was disrupted.

Recently the two phenotypes (suppression of homoeologous crossover (Ph1) in wheatwild relative hybrids, and the presence of meiotic abnormalities in $50 \%$ of meiocytes in the $5 \mathrm{~B}$ deletion mutants themselves) have been defined using a series of $5 \mathrm{~B}$ deletions to a $0.5 \mathrm{Mb}$ region of chromosome $5 \mathrm{~B}$ containing a copy of the major meiotic gene ZIP4 (TaZIP4-B2) [14,16-19]. Genome analysis revealed that hexaploid wheat possessed a further ZIP4 gene on each of the group 3 chromosomes. Analysis by the International Wheat Genome Sequencing Consortium [20] confirmed that on wheat polyploidisation, TaZIP4$B 2$ was derived from ZIP4 3B (TaZIP4-B1) through a trans-duplication event. ZIP4 is a protein containing tetratricopeptide repeats (TPRs), which can assemble protein complexes promoting homologous crossover in plants [21,22]. In the wheat CRISPR Tazip4-B2 deletion mutant, $50 \%$ of meiocytes exhibit meiotic abnormalities (the phenotype reported by Roberts et al. [15]) [19], demonstrating that TaZIP4-B2 promotes homologous pairing, synapsis and crossover. However, when the CRISPR Tazip4-B2 deletion mutant is crossed with a wild relative to form a hybrid, homoeologous crossover also takes place [19], implying a role for TaZIP4-B2 in suppression of homoeologous crossover. Thus, the duplication of ZIP4 on wheat polyploidisation led to an adaptation during meiosis I, preventing meiotic disruption by promoting homologous pairing, synapsis and crossover, and suppressing homoeologous crossover. 
Following meiosis I, the reductional division during wheat male meiosis (meiosis II), leads to the formation of tetrads each containing four microspores, which degenerate to release individual uninucleate microspores. Each microspore undergoes mitotic divisions to produce a mature trinucleate pollen grain, with one vegetative nucleus and two generative nuclei or sperm cells. Reductional division in wheat female meiosis results in a T-shaped tetrad, containing 4 megaspores. Only one of the megaspores develops into an embryo sac, with the remaining 3 megaspores degenerating. Hence, whilst all four products of meiosis survive on the male side, only one survives on the female side. Meiosis is an essential process for the formation of gametes. Thus, meiotic abnormalities or genetic disruptions are likely to result in reduced fertility. Meiotic abnormalities on the male side may be associated with variable sized and/or inviable pollen grains, and on the female side, with a partial reduction in grain number or complete sterility [23-25].

In the polyploid literature, it is often stated that meiotic adaptation is important for polyploid fertility. However, it has not previously been possible to determine the effect of an actual meiotic adaptation. The availability of a CRISPR deletion mutant for the duplicated TaZIP4-B2 copy allows us to assess the effect of this meiotic adaptation on the correct segregation of chromosomes, effective production of balanced gametes, and hence preservation of pollen viability and grain number in this major global crop. As part of this assessment, a pollen profiling method has been developed and exploited to compare pollen profiles of different mutants in hexaploid (and tetraploid) wheat.

\section{Materials and Methods}

\subsection{Plant Material}

Three different Tazip4-B2 mutants were used in this study: (1) ph1b: a hexaploid wheat T. aestivum cv. Chinese Spring mutant [13]; (2) CRISPR Tazip4-B2: a hexaploid wheat T. aestivum $\mathrm{cv}$. Fielder mutant with a CRISPR-induced deletion of 38 amino acids ( $\mathrm{A}^{104}$ to $\mathrm{E}^{141}$ ) from the TaZIP4-B2 protein [19]; (3) ph1c: a tetraploid wheat T. turgidum subsp. Durum cv. Senatore Cappelli mutant [26].

\subsection{Pollen Profiling}

Ten plants for each genotype were grown in a controlled environment room (CER) at $20{ }^{\circ} \mathrm{C}$ (day) and $15{ }^{\circ} \mathrm{C}$ (night) (16-hr photoperiod, $70 \%$ humidity). Mature yellow anthers were collected just before shedding pollen, from five main florets at the middle portion of the first spike of each plant. Each of three anthers from the same floret were placed in an Eppendorf containing $0.5 \mathrm{~mL} 70 \%$ ethanol and stored at $4{ }^{\circ} \mathrm{C}$. Pollen grains were released from anthers by sonication and the sonicated pollen samples filtered through $200 \mu \mathrm{m}$ sieves using $100 \mathrm{~mL}$ Coulter Isoton II diluent (Beckman Coulter). Size and number of filtered pollen grains were measured using a Coulter counter (Multisizer 4e, Beckman Coulter Inc., Brea, CA, USA), fitted with a $200 \mu \mathrm{m}$ aperture tube, with Isoton II diluent (using the following settings: Control mode: volumetric; Analytic volume: $2000 \mu \mathrm{L}$; Electrolyte volume: $100 \mathrm{~mL}$; Size bins $=400$ from $4 \mu \mathrm{m}$ to $120 \mu \mathrm{m}$; Current: $1600 \mu \mathrm{A}$; Stirring speed: $20 \mathrm{CW}$ ). For each sample, the measured pollen number distribution over size bins was exported into a csv file, then an R script (Text S1) used to extract and calculate plotdifferential pollen size distribution and pollen number per anther from the raw data files for each genotype.

\subsection{Pollen Viability}

Pollen viability was assessed using Alexander stain [27]. Fresh wheat pollen grains from three anthers were shed on a droplet of Alexander stain placed on a microscope slide and images taken for scoring. Three biological replicates, each with $>1000$ pollen grains were analysed for each genotype. 


\subsection{Grain Number Per Spike Assessment}

In the CER, plants were grown at $20^{\circ} \mathrm{C}$ (day) and $15^{\circ} \mathrm{C}$ (night) (16-h photoperiod, $70 \%$ humidity). In the glasshouse, $11-15$ plants from each genotype were grown at $22^{\circ} \mathrm{C}$ (day) and $17{ }^{\circ} \mathrm{C}$ (night) (16-h photoperiod, $70 \%$ humidity). In both experiments, the first three bagged spikes from each plant were harvested when fully dried, and threshed separately after counting spikelet number. The number of grains per spike was then measured using the MARVIN grain analyser (GTA Sensorik GmbH, Neubrandenburg, Germany). Grain number per spike ((actual grain number per spike/expected grain number per spike) $\times 100$ ) was normalised in order to eliminate the effect of different number of spikelets per spike on grain number. Expected grain number was calculated by multiplying number of spikelets by three, considering that each spikelet has three main fertile florets.

\subsection{Female Sterility Assessment}

Female sterility was assessed through the emasculation/pollination method, using the CRISPR Tazip4-B2 mutant as both pollen donor and recipient. For each pollination experiment, at least twelve spikes were emasculated at the heading stage when the spike had fully emerged from the flag leaf and anthers were still green with a tight stigma. Spikelets located at the tip and base of the spike, and florets in the centre of each spikelet were removed before emasculation. Emasculated spikes were covered with crossing bags. Receptive and mature stigma were pollinated using fresh pollen grains collected from fully mature anthers. All emasculations and pollinations were undertaken in the morning. Grain number per spike was normalised by dividing the number of grains by the number of pollenated florets per spike.

\subsection{Seed Germination Rate}

Seeds resulting from the emasculation/pollination experiment were disinfected with $5 \%$ Sodium Hypochlorite, washed with distilled water, placed on wet filter paper in Petri dishes $(9 \mathrm{~cm}$ diameter), wrapped with aluminium foil and placed in a growth chamber for 10 days $\left(22^{\circ} \mathrm{C}\right)$. Each Petri dish represented a replicate containing 15 seeds originating from the same spike. Five replicates were used for each treatment. Seeds were considered to have germinated after radicle emergence. The germination percentage was calculated as (number of seeds germinated/total seeds) $\times 100$.

\subsection{Meiotic Analysis}

Anthers were collected and fixed as previously described [28]. Cytological analysis of Pollen Mother Cells using the Feulgen technique was performed as previously described [29]. FISH preparations of repetitive sequences, 4P6 and pTa71, and FISH analysis of anthers fixed at the tetrad stage were as described previously [30]. Digoxigenin-labelled probes were detected with anti-digoxigenin-fluorescein Fab fragments (Sigma), and Biotinlabelled probes were detected with Streptavidin-Cy5 (Thermo Fisher Scientific, Waltham, MA, USA).

\subsection{Image Processing}

Pollen grains and Pollen Mother Cells stained by the Feulgen technique were imaged using a LEICA DM2000 microscope (Leica Microsystems, http:/ / www.leica-microsystems. $\mathrm{com} /$, accessed on 31 March 2021), equipped with a Leica DFC450 camera and controlled by LAS v4.4 system software (Leica Biosystems, Wetzlar, Germany). Tetrads labelled by FISH were imaged using a Leica DM5500B microscope equipped with a Hamamatsu ORCAFLASH4.0 camera and controlled by Leica LAS X software v2.0. Z-stacks were processed using the 561-deconvolution module of the Leica LAS X Software package. Images were processed using Adobe Photoshop CS5 (Adobe Systems Incorporated, San Jose, CA, USA) extended version $12.0 \times 64$. 


\subsection{TaZIP4 Protein Sequence Analysis}

DNA, CDS and protein sequences of the four TaZIP4 homologues were retrieved from the Ensembl Plants database for Triticum aestivum (IWGSC v1.1 gene annotation [20]). Multiple sequence alignments of coding sequences (CDS) and protein sequences of TaZIP4-A1 (TraesCS3A02G401700.3), TaZIP4-B1 (TraesCS3B02G434600.2), TaZIP4-B2 (TraesCS5B02G25 5100.1), TaZIP4-D1 (TraesCS3D02G396500.2) and the mutant CRISPR Tazip4-B2 [19], were performed using the Clustal X programme (version 2; [31,32]). Programmes used for protein analysis are described below.

\section{Results}

\subsection{Divergence and the CRISPR Deletion Occur within the TaZIP4-B2 TPR Domain}

The InterProScan [33] and PFAM programmes identified a single highly conserved SPO22 domain (PF08631) within the EBI database ZIP4s. This SPO22 domain was composed of tetratricopeptide repeats (TPRs) of 34 amino acids. A second SPO22 domain of low significance was observed in tandem with the highly conserved SPO22 domain in many ZIP4s. Only PFAM classified this second SPO22 domain as being significant for a limited number of these ZIP4s. ZIP4 function is dependent on these SPO22 TPRcontaining domains, due to their involvement in assembling protein complexes $[34,35]$. The annotation programmes enabled us to assess whether the divergence of TaZIP4-B2 from its chromosome group 3 homoeologues (TaZIP4-A1, TaZIP4-B1 and TaZIP4-D1) occurred within the SPO22 domain. Similarly, we used the annotation programmes to determine the site of the in-frame 38 amino acid CRISPR deletion of Tazip4-B2 [19] relative to the SPO22 domain. Multiple sequence alignments showed that TaZIP4-B2 was quite divergent from the other group 3 homoeologues (Figure 1a). The percentage of identity between TaZIP4-B2 and the other homoeologues did not exceed $85.8 \%$ in coding sequences (CDS) and $92.2 \%$ in protein sequences, whereas the inter-identity of TaZIP4-A1, TaZIP4-B1 and TaZIP4-D1 ranged from $94.9-96.3 \%$ for CDS sequences and from $96.8-97.5 \%$ for protein sequences (Table S1). The InterProScan and PFAM programmes identified the highly conserved SPO22 domain within all the wheat ZIP4s, with PFAM identifying a second SPO22 domain in tandem (Figure 1b). TPRpred [36] identified 12 TPRs within wheat ZIP4-B1 (Figure 1c), showing that up to half of total ZIP4-B1 protein consisted of TPRs. However, the region of TaZIP4-B2 corresponding to the 3rd TPR of ZIP4-B1 within the highly conserved SPO22 domain, was no longer identified as a TPR by TPRpred. Thus, within wheat TaZIP4-B2, only 11 TPRs were identified. The 2nd and 4th TPRs of TaZIP4-B2 and TaZIP4-B1 also exhibited some divergence with respect to each other. As a result of this divergence, the MARCOIL programme $[36,37]$ suggested an altered conformation within the conserved SPO22 domain of TaZIP4-B2 compared to the domains of TaZIP4-B1 and other ZIP4 homoeologues (Figure 1d). Thus, duplication of TaZIP4-B2 from TaZIP4-B1 led to TPR divergence (especially the 3rd TPR (Table S1)), giving rise to associated changes in protein conformation. This predicts that TaZIP4-B2 function may be altered with respect to that of its chromosome group 3 homoeologues. The 38 amino acid in-frame CRISPR deletion (within the CRISPR Tazip4-B2) covered the 1st TPR, indicating that the deletion did indeed affect the SPO22 domain and correlated with complete loss of the TaZIP4-B2 phenotype [19].

\subsection{Effect of the TaZIP4-B2 Deletion on Meiotic and Tetrad Stages}

Average meiotic scores from Tazip4-B2 mutants at metaphase I were reported previously $[19,38]$. However, the present study required meiotic scores from individual meiocytes from Tazip4-B2 mutants at metaphase I, in order to relate meiotic abnormalities observed during metaphase I with those observed at subsequent stages. Both CRISPR Tazip4-B2 [19] and ph1b [13] mutants were exploited. The $p h 1 b$ mutant carries a $59.3 \mathrm{Mb}$ deletion encompassing some 1187 genes, including TaZIP4-B2 [14]. Meiotic scores from individual meiocytes at metaphase I from CRISPR Tazip4-B2 [19], ph1b [38] and their respective wild type plants are provided in Table 1 and Table S2 and visualised in Figure 2. Examples of meiotic configurations of the CRISPR Tazip4-B2 mutant and wild type (WT 
Fielder) plants at metaphase I are provided in Figure 3a,b. More than half of the scored meiocytes in the CRISPR Tazip4-B2 and ph1b mutants had meiotic abnormalities (Figure 2). Overall, univalents and/or multivalents were observed in $56 \%$ of both the CRISPR Tazip4$B 2$ and $p h 1 b$ mutant meiocytes. Univalents were present in $49 \%$ and $43 \%$ of meiocytes at metaphase I (average per meiocyte 1.16 and 0.8) for the CRISPR Tazip4-B2 and ph1b mutants, respectively. Multivalents were present in $32 \%$ and $43 \%$ (average 0.39 and 0.53 per meiocyte) of the CRISPR Tazip4-B2 and ph1b mutant meiocytes, respectively. The slight excess of multivalents and lack of univalents in the $p h 1 b$ mutant compared to the CRISPR Tazip4-B2 mutant may be simply due to accumulation of the extensive rearrangements observed and reported in this mutant [14], which can form multivalents at metaphase I (Table 1 and Table S2). The excess of multivalents in the ph1b mutant could also be explained by additional unknown deleted genes within the $59.3 \mathrm{Mb} 5 \mathrm{~B}$ deletion, but the issue cannot be resolved by just scoring for the presence or absence of multivalents at metaphase I, as scoring multivalents alone would fail to distinguish between different deletion mutants covering variable lengths of the long arm of 5B [15]. Thus, the deletion of TaZIP4-B2 leads to nearly half of meiocytes possessing univalents as a result of pairing and crossover failure, and a third of meiocytes possessing multivalents as a result of incorrect pairing and crossover.

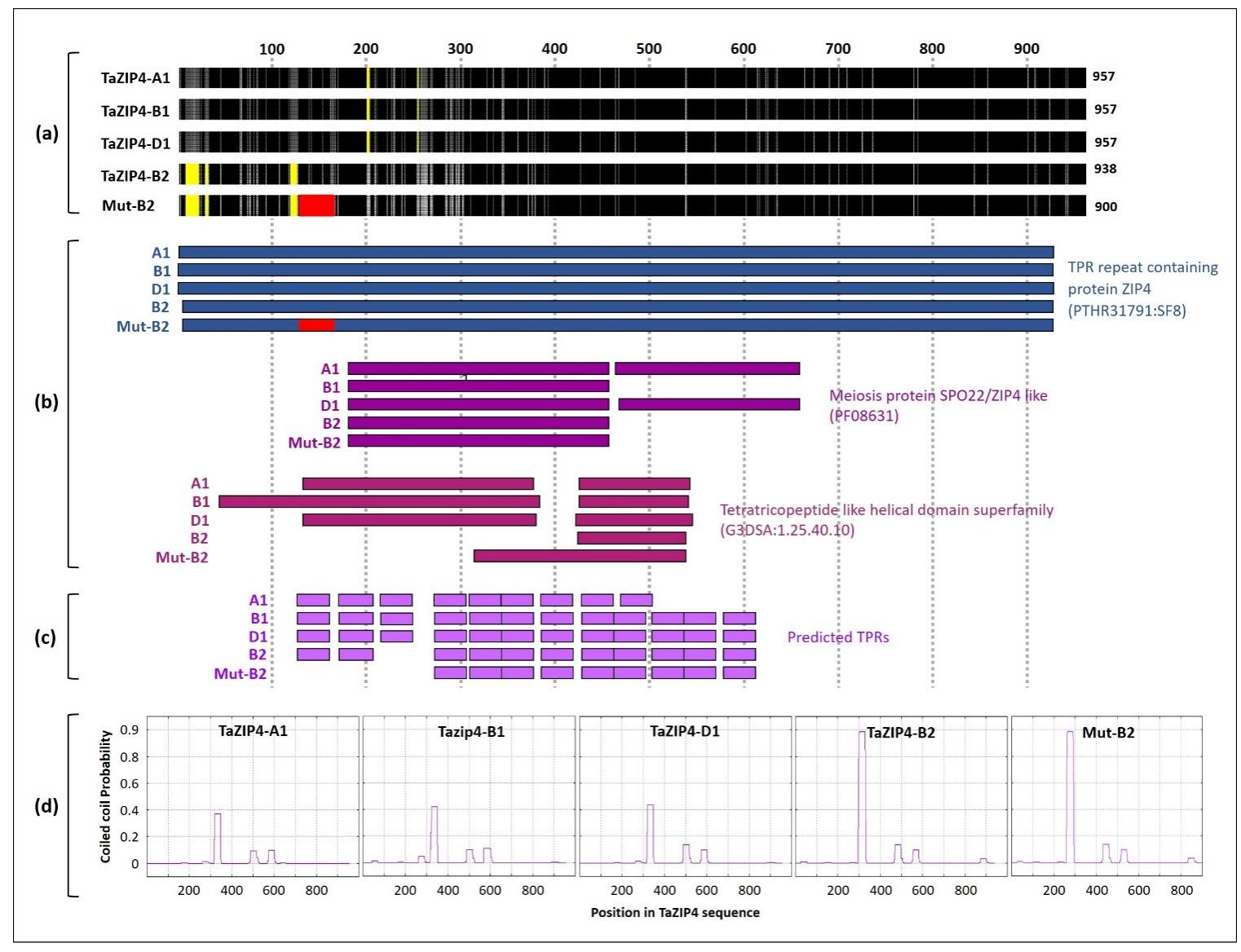

Figure 1. Comparison of the TaZIP4 homoeologous proteins. (a) Multiple amino acid sequence alignment of the TaZIP4 homoeologous proteins using ClustalX software (version 2.0; [31,32]). Regions with identical amino acid sequences across the four proteins are in black. Grey colour refers to sequences with similar amino acid properties and light grey refers to sequences with different amino acid properties. Yellow regions indicate gaps in sequence alignment. Mut-B2 refers to Tazip4-B2 in the CRISPR mutant. Red region shows the 38-amino acids segment deleted from the protein of the CRISPR Tazip4-B2 mutant. (b) Predicted functional domains in the TaZIP4 proteins using the online InterPro software (version 82.0; [33]). (c) Predicted Tetratricopeptide Repeats (TPRs) in the TaZIP4 proteins using the online TPRpred program (version 11.0; [36]. (d) Predicted coiled coil domains in the TaZIP4 proteins using the online MARCOIL programme [36,37]. 


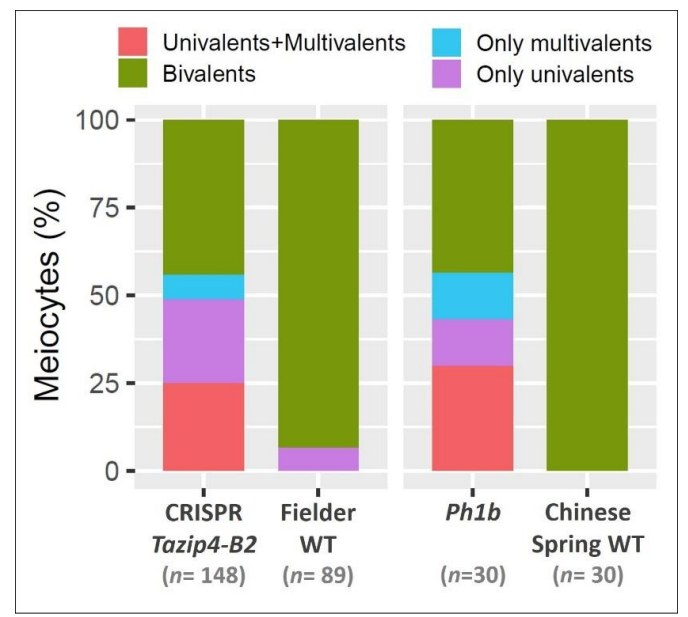

Figure 2. The percentage of meiocytes with meiotic abnormalities from the CRISPR Tazip4-B2 and ph1b mutants, and their wild types. Data used to produce this figure is taken from Rey et al. [19] and Martín et al. [38]. $n$ refers to the number of scored meiocytes.

Meiotic aberrations at metaphase I (univalents and multivalents) can lead to imbalanced chromosomal segregation at anaphase I, with subsequent disruption to the post-meiotic process. Giorgi had already reported the presence of lagging chromosomes at anaphase I and micronuclei at the tetrad stage in the tetraploid $P h 1$ deletion mutant (ph1c) carrying a large chromosomal deletion covering the TaZIP4-B2 region [26]. Therefore, the stages following metaphase I were studied in both the WT Fielder and the CRISPR Tazip4-B2 mutant. In WT Fielder, homologous chromosomes (homologues) appear connected to each other by one or mostly several chiasmata (Figure 3a), with only an occasional univalent being present during metaphase I. Each homologue separates to a different pole of the nucleus during anaphase I, resulting in equal separation of homologues (Figure 3c,e). After the second meiotic division, tetrads with four balanced gametes each are formed (Figure 3g). In the CRISPR Tazip4-B2 mutant, univalents, multivalents and a global reduction in the number of chiasmata were observed at metaphase I (Figure 3b), as previously reported [19]. Although unbalanced segregation of chromosomes would be expected during anaphase I as a consequence of disrupted crossover distribution, observed disruptions were greater than expected, with regular presence of lagging chromosomes, split sister chromatids and chromosome fragmentation (Figure 3d,f). The high number of micronuclei (MN) observed in tetrads, the final product of meiosis, was the most surprising result (Figure $3 \mathrm{~h}, \mathrm{j}$ ). It is not unusual to find an occasional MN in wheat. Indeed, some were found in the WT Fielder analysed in this study (less than $5 \%$ of tetrads), probably due to an occasional univalent observed at metaphase I. However, in the CRISPR Tazip4-B2 mutant, it was striking that more than $50 \%$ of tetrads showed at least one MN (Figure 3i); one, two and less frequently three MN per tetrad were detected. Fluorescent in situ hybridisation (FISH) was performed on tetrads from both the WT Fielder and CRISPR Tazip4-B2 mutant, using the repetitive probes 4P6 [39] and pTa71 [40], in order to assess the level of mis-segregation and to ascertain whether specific chromosomes were involved in MN formation. Probe 4P6 labels seven interstitial sites on D genome metaphase I chromosomes, while pTa71 labels the NOR (Nucleolar Organiser Region) on the 1BS, 6BS and 5DS metaphase I chromosomes. A 4P6 signal was observed in $23.8 \%$ MNs, confirming a D genome chromosome origin, and a pTa71 signal in $17.5 \% \mathrm{MNs}$, indicating that some chromosomes were carrying a NOR. This suggests that $\mathrm{MN}$ formation did not result from a single specific pair of homologues being univalent at metaphase I, but rather from different pairs of homologues being univalent in individual meiocytes. Morrison [41] observed that univalents at metaphase I lagged at anaphase I, and then formed $\mathrm{MN}$ at the dyad stage. Such MNs were then maintained until the tetrad stage, when they were lost with the separation of the four microspores. Morrison [41] also observed a direct correlation between numbers of univalents at metaphase I and percentage 
of tetrads with MN. As such, our observations are consistent with those of Morrison [41], in that $56 \%$ of Tazip4-B2 mutant meiocytes exhibited abnormalities at metaphase I, while 50\% of tetrads subsequently possessed MN.
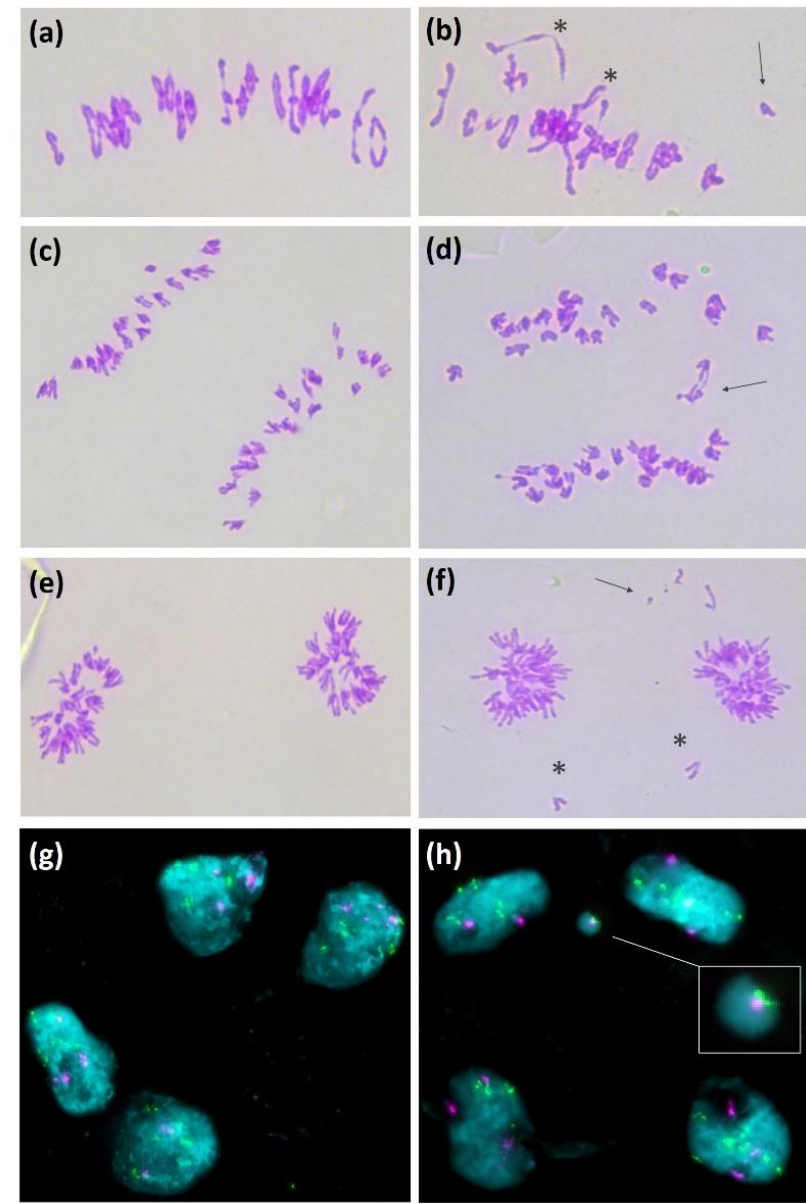

\begin{tabular}{|l|c|c|}
\hline (i) & $\begin{array}{c}\text { FIELDER } \\
\text { WT }\end{array}$ & $\begin{array}{c}\text { CRISPR } \\
\text { Tazip4-B2 }\end{array}$ \\
\hline $\begin{array}{c}\text { \% Tetrads } \\
\text { with MN }\end{array}$ & 4.9 & 50.6 \\
\hline $\begin{array}{c}\text { Total No. } \\
\text { Tetrads }\end{array}$ & 181 & 156 \\
\hline $\begin{array}{c}\text { No. Tetrads } \\
\text { with MN }\end{array}$ & 9 & 79 \\
\hline
\end{tabular}

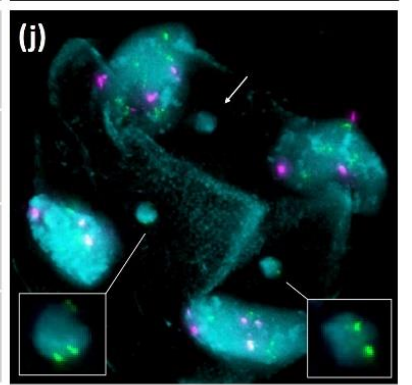

Figure 3. Meiosis in wild type (WT) Fielder $(\mathbf{a}, \mathbf{c}, \mathbf{e}, \mathbf{g})$ and the CRISPR Tazip4-B2 Fielder mutant $(\mathbf{b}, \mathbf{d}, \mathbf{f}, \mathbf{h}, \mathbf{j})$. (a) Metaphase I in WT Fielder showing 19 ring bivalents and 3 rod bivalents. (b) Metaphase I in CRISPR Tazip4-B2 mutant with the presence of multivalents (asterisk) and univalent (arrow). (c) Anaphase I in WT displaying equal separation of homologous chromosomes to both poles. (d) Anaphase I in CRISPR Tazip4-B2 mutant showing lagging chromosomes. (e) Late anaphase I in WT. (f) Late anaphase I in CRISPR Tazip4-B2 mutant showing some chromosome fragments in the periphery of equatorial plate (arrow) and chromosome mis-division in the equatorial plate (asterisk) which will not be included in any of the dyads. $(\mathbf{g}, \mathbf{h})$ Tetrads shown in cyan, with repetitive probe 4P6 (in green) and pTa71 (in magenta). (g) Tetrad from WT showing 4 normal microspores. (h) Tetrad in CRISPR Tazip4-B2 mutant showing 1 micronucleus (MN) displaying 4P6 and pTa71 signals. (j) Tetrad in CRISPR Tazip4-B2 mutant showing 3 micronuclei, 2 of them presenting 4P6 signals. (i) Close to 5\% of the tetrads showing MN in WT, while $50 \%$ of tetrads in the CRISPR Tazip4-B2 mutant possessing 1, 2 or $3 \mathrm{MN}$. 
Table 1. Summary of the meiotic scores for the two Tazip4-B2 mutants and their corresponding wild types.

\begin{tabular}{ccccccc}
\hline Genotype & Univalents & Multivalents & $\begin{array}{c}\text { Rod } \\
\text { Bivalents }\end{array}$ & $\begin{array}{c}\text { Ring } \\
\text { Bivalents }\end{array}$ & $\begin{array}{c}\text { Defective } \\
\text { Meiocytes *\%) }\end{array}$ & Reference \\
\hline Fielder WT ** & $0.16 \pm 0.07$ & $0 \pm 0$ & $1.37 \pm 0.13$ & $19.52 \pm 0.14$ & 6.70 & {$[19]$} \\
CRISPR Tazip4-B2 & $1.16 \pm 0.12$ & $0.39 \pm 0.05$ & $4.93 \pm 0.15$ & $14.84 \pm 0.19$ & 56.00 & \\
Chinese Spring & $0 \pm 0$ & $0 \pm 0$ & $1 \pm 0.20$ & $20 \pm 0.20$ & 0.00 & {$[38]$} \\
ph1b & $0.80 \pm 0.19$ & $0.53 \pm 0.12$ & $4.73 \pm 0.26$ & $14.83 \pm 0.33$ & 56.60 & \\
\hline
\end{tabular}

${ }^{*}$ Meiocytes with meiotic aberrations (univalents and multivalents) thus have incorrect chromosome pairing. ${ }^{* *}$ This is a CRISPR transgenic Fielder without TaZIP4-B2 knockout.

\subsection{Effect of the Tazip4-B2 Deletion on Wheat Grain Number Per Spike (Grain Setting)}

The presence of $\mathrm{MN}$ in 50\% tetrads suggested unbalanced microspores, which could also affect grain set. Two experiments (CER and glasshouse) were therefore conducted to assess the effect of deleting Tazip4-B2 on grain set. In these experiments, grain setting analysis was performed on both the CRISPR Tazip4-B2 mutant and the ph1b hexaploid wheat mutant carrying the $59.3 \mathrm{Mb}$ deletion covering Tazip4-B2. Spikelet number was recorded, as well as number of grains per spike for the first three spikes from each mutant and their corresponding WTs. The normalized grain number per spike was used to compare genotypes. Both CER and glasshouse experiments confirmed significantly reduced seed set in both Tazip4-B2 mutants compared to their corresponding WT $(p<0.01)$ (Figure 4a; Table 2). Under CER conditions, the grain number per spike was reduced by $36 \%$ in the CRISPR Tazip4-B2 mutant compared to the WT Fielder, and by $42 \%$ in the $p h 1 b$ mutant compared to the Chinese Spring WT. Under glasshouse conditions, the grain number per spike was reduced by $44 \%$ in the CRISPR Tazip4-B2 and $43 \%$ in the $p h 1 b$ mutant, compared to their corresponding WTs. There was no significant difference between the CER and glasshouse growth conditions on grain settings for each genotype (Table 2 and Table S3). Thus, the CRISPR deletion of TaZIP4-B2 in hexaploid wheat resulted in 56\% of meiocytes exhibiting meiotic abnormalities, $50 \%$ of tetrads exhibiting micronuclei, and up to $44 \%$ reduction in grain set. Similarly, the ph1b mutant also exhibited $56 \%$ meiocytes with meiotic abnormalities and up to $43 \%$ reduction in grain set.

\subsection{Pollen Contributes to the Tazip4-B2 Effect on Grain Setting}

As previously described, on the female side, only one of the 4 megaspores develops into the embryo sac, with the 3 remaining megaspores degenerating following the tetrad stage. This contrasts with the male side, where all four products of meiosis survive to go through pollen development. It is possible that on the female side, some of the unbalanced megaspores are aborted, so that the near $50 \%$ reduction in grain set observed in the CRISPR Tazip4-B2 mutant mostly results from pollination with less viable pollen. An emasculation/pollination experiment was therefore conducted, using the CRISPR Tazip4$B 2$ mutant and its corresponding WT. The experiment involved pollinating WT plants with WT or Tazip4-B2 mutant pollen, or the Tazip4-B2 mutant with WT pollen. Results showed that the lowest percentage of grain number per spike occurred when WT plants were pollinated with CRISPR Tazip4-B2 mutant pollen (Figure 4b; Table S4), and that this grain set was significantly lower than that produced by pollinating WT plants with WT pollen $(37.8 \%$ difference; $p<0.01$ ) (Figure $4 \mathrm{~b})$. In contrast, when the Tazip4-B2 mutant was pollinated with WT pollen, the reduction in grain set was not significantly different to when WT plants were pollinated with WT pollen (Table S4). These results suggest that most of the reduced grain number in the CRISPR Tazip4-B2 mutant is due to its being pollinated with less viable pollen, rather than it all being due to impaired female gametogenesis. Thus, meiotic abnormalities associated with TaZIP4-B2 deletion may have a greater subsequent effect on male gametogenesis than on female gametogenesis.

The maternal and paternal effects of TaZIP4-B2 on seed embryo development were assessed by germinating the resulting seeds from each of the above pollination experiments. 
Germination rates from each of the pollination experiments were not significantly different (Figure 4c; Table S5). Thus, there was no apparent negative effect of the CRISPR Tazip4-B2 mutation on the germination of seed derived from WT plants pollinated with Tazip4-B2 mutant pollen, or from Tazip4-B2 mutants pollinated with WT pollen.

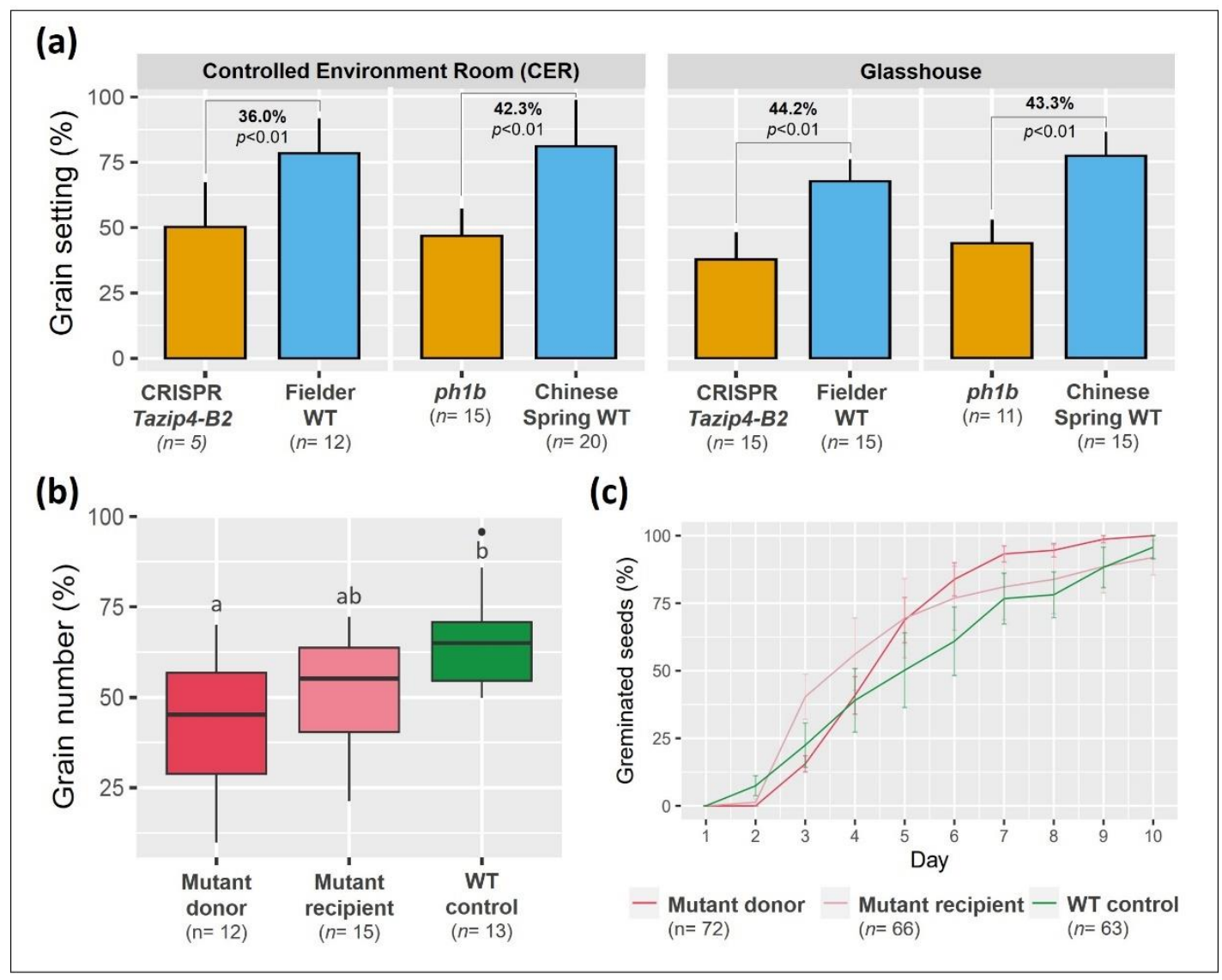

Figure 4. The effect of TaZIP4-B2 on grain setting. (a) Grain number per spike in the two Tazip4-B2 mutants and their WT controls under CER and glasshouse growth conditions. Percentages indicate the difference in grain setting between each mutant and its WT. $n$ refers to the number of biological replicates. (b) Normalised grain number per spike in the three treatments of the emasculation/pollination experiment. Treatments with the same letter are not significantly different. $n$ refers to the number of emasculated/pollenated spikes. (c) Seed germination rates resulting from different pollen donor and pollen recipient genotypes. $n$ refers to the number of seeds included in the seed germination experiment.

Table 2. Mean Normalized grain number per spike for the two Tazip4-B2 mutants and their corresponding wild types under CER and glasshouse growth conditions. $\mathrm{N}$ is the number of biological replicates per genotype. Mean values with standard deviation are shown. Treatments with the same letter are not significantly different.

\begin{tabular}{ccccc}
\hline \multirow{2}{*}{ Genotype } & \multicolumn{2}{c}{ Controlled Environment Room (CER) } & \multicolumn{2}{c}{ Glasshouse } \\
\cline { 2 - 5 } & $\mathbf{N}$ & Normalized Grain Number Per Spike & $\mathbf{N}$ & Normalized Grain Number Per Spike \\
\hline CRISPR Tazip4-B2 & 5 & $50.2 \pm 16.7^{\mathrm{b}, \mathrm{c}, \mathrm{d}}$ & 15 & $37.7 \pm 1.0^{\mathrm{d}, \mathrm{e}}$ \\
cv. Fielder WT & 12 & $78.5 \pm 12.9^{\mathrm{a}}$ & 15 & $67.6 \pm 07.9^{\mathrm{a}, \mathrm{b}}$ \\
ph1b & 15 & $46.7 \pm 1.0^{\mathrm{c}, \mathrm{d}}$ & 11 & $43.8^{\mathrm{a}} \pm 08.6^{\mathrm{c}, \mathrm{d}}$ \\
cv. Chinese Spring WT & 20 & $80.9 \pm 17.3^{\mathrm{a}}$ & 15 & $77.3 \pm 08.8^{\mathrm{a}}$ \\
\hline
\end{tabular}

\subsection{A Pollen Profiling Approach Reveals 50\% Tazip4-B2 Mutant Pollen Is Small}

Meiotic abnormalities in 56\% meiocytes lead to mis-segregation of chromosomes and $50 \%$ tetrads with micronuclei. The Tazip4-B2 mutant has up to a $44 \%$ reduction in grain number. The emasculation and pollination experiment suggests that most of this effect is the result of reduced pollen viability. We therefore developed a pollen profiling approach 
to study the effect of the CRISPR Tazip4-B2 mutant on wheat pollen size and number, based on approaches previously described by Lamborn et al. [42] and De Storme et al. [43], but modified to allow simultaneous and precise measurement of pollen grain size and pollen number per anther. The modified method was validated using pollen samples from five different wheat varieties, namely Cadenza, Fielder and Paragon (hexaploid), Cappelli and Kronos (tetraploid) and one hexaploid wheat landrace (Chinese Spring). Fully mature anthers were collected from the middle portion of the first ear of each plant, just before opening and pollen shedding, and stored in $70 \%$ ethanol. The samples could be stored in ethanol for a long period before analysis, without significant effect on pollen measurement accuracy. Pollen profiles of anther samples in 70\% ethanol from the same genotype after different storage periods (of up to one month) are shown in Figure S1. Sonication was used to ensure that all pollen grains were released from anthers, ensuring accurate measurement of pollen number per anther. Pollen size measurements from the six wheat varieties showed that the average pollen size in the hexaploid wheats was $49.0 \pm 0.4 \mu \mathrm{m}$, (ranging from $48.6 \pm 1.2 \mu \mathrm{m}$ to $49.5 \pm 1.1 \mu \mathrm{m}$ in Chinese Spring and Paragon, respectively), while in the tetraploid wheats it was $44.6 \pm 0.2 \mu \mathrm{m}(44.8 \pm 1.4 \mu \mathrm{m}$ and $44.4 \pm 1.4 \mu \mathrm{m}$ in Cappelli and Kronos, respectively) (Table 3 and Table S6), in keeping with previously reported wheat pollen sizes $[44,45])$. Pollen profiles of the hexaploid and tetraploid wheat varieties are shown in Figure 5a.

Pollen number per anther varied between different wheat varieties (Figure 5b). The average number of pollen grains per anther was $2709 \pm 614$ (ranging from $1973 \pm 272$ in Fielder to $3515 \pm 260$ in Cappelli) (Table 3). There was no correlation between number of pollen grains and polyploidy level, as there were no significant differences between hexaploid wheats (Cadenza and Paragon) and tetraploid wheats (Kronos and Cappelli) (Table S6). Nevertheless, pollen numbers were in keeping with those reported in a previous study [46]. The pollen profiling method allowed us to compare pollen grain size distribution and pollen number from three different Tazip4-B2 mutants with the relevant WT controls. Pollen was collected from full mature anthers (just before opening) for each of the Tazip4-B2 mutants (CRISPR Tazip4-B2; ph1b hexaploid wheat mutant carrying a 59.3 Mb chromosome 5B deletion covering TaZIP4-B2; ph1c tetraploid mutant carrying a large deletion of chromosome 5B covering TaZIP4-B2) and their WTs (T. aestivum cv. Chinese Spring; T. turgidum subsp. Durum cv. Senatore Cappelli [26]; T. aestivum cv. Fielder, respectively). Ten to twelve biological replicates for each of the six genotypes were included in the experiment. Pollen grain size and number were measured from five samples of each biological replicate using the Coulter counter Multisizer 4e. In this study, a mean of 10,948 \pm 2063 pollen grains were measured from each genotype (average $1121 \pm 208$ pollen grains per plant) (Table 4). The three Tazip4-B2 mutants showed a consistent and similar pollen profile comprising of two distinct peaks. The first peak represented pollen grains with grain size distribution similar to WT pollen and the second a group of pollen grains with smaller grain size (Figure 6a). Accordingly, there were significant differences between the mean pollen grain size of each of the mutants $p h 1 b, p h 1 c$ and CRISPR Tazip4-B2 and their corresponding WTs $(p<0.01)$ (Table 4$)$. More than $48 \%$ of pollen grains in the CRISPR Tazip4-B2 hexaploid mutant samples were smaller in size $(\leq 42 \mu \mathrm{m})$. A similar percentage of small pollen grains (47\%) was found in the $p h 1 b$ hexaploid mutant samples. However, small pollen grains $(\leq 38 \mu \mathrm{m})$ were found in a lower percentage $(34 \%)$ in the ph1c tetraploid mutant samples (Figure 6b). The mean pollen number per anther ranged from $2317 \pm 333$ to $3713 \pm 497$ in the CRISPR Tazip4-B2 and ph1c mutants, respectively (Figure 6c). However, no significant differences were observed between any of the Tazip4-B2 mutants and their WT controls (Table 4). Detailed datasets of pollen size, pollen number per anther and percentage of small pollen grains for each TaZIP4-B2 mutant and its respective wild type can be found in Table S7.

Viability of pollen from the CRISPR Tazip4-B2, and ph1b hexaploid mutants, as well as the ph1c tetraploid mutant, was assessed using Alexander staining. More than 3000 pollen grains were scored for each genotype (from three biological replicates) after Alexander 
staining and image acquisition. Pollen coloured dark magenta after treatment with Alexander stain was considered viable, whereas light blue-green stained pollen was considered unviable (Figure 7a). Analysis revealed similar percentages of unviable pollen grains in all Tazip4-B2 mutants (Figure 7c), with 28\% in the CRISPR-Tazip4-B2 mutant, 25.8\% in the ph1b mutant and $22.8 \%$ in the ph1c mutant pollen being unviable (Table S8). In all cases, the level of unviable pollen grains in the mutants was significantly higher than that in the WTs $(p<0.01)$, which did not exceed 3.3\% on average. Developmental pollen stages were also assessed in the TaZIP4-B2 mutants. Pollen grains from fully mature anthers from the Fielder mutant CRISPR Tazip4-B2 and the WT Fielder were stained selectively for DNA using Feulgen stain. Results from the WT showed normal trinucleate pollen grains, whereas about half of the pollen grains in the mutant were immature and/or abnormal (Figure $7 \mathrm{~b}$ ). Thus, the pollen profiling analysis revealed that around half the pollen from the CRISPR Tazip4-B2 and ph1b hexaploid wheat mutants had similar pollen profiles, with around half the pollen grains being abnormally small. The Alexander and Feulgen staining methods provided further information revealing that the small pollen grains in the CRISPR Tazip4-B2 and $p h 1 b$ mutants were a mixture of both immature (unfunctional) and unviable pollen grains.

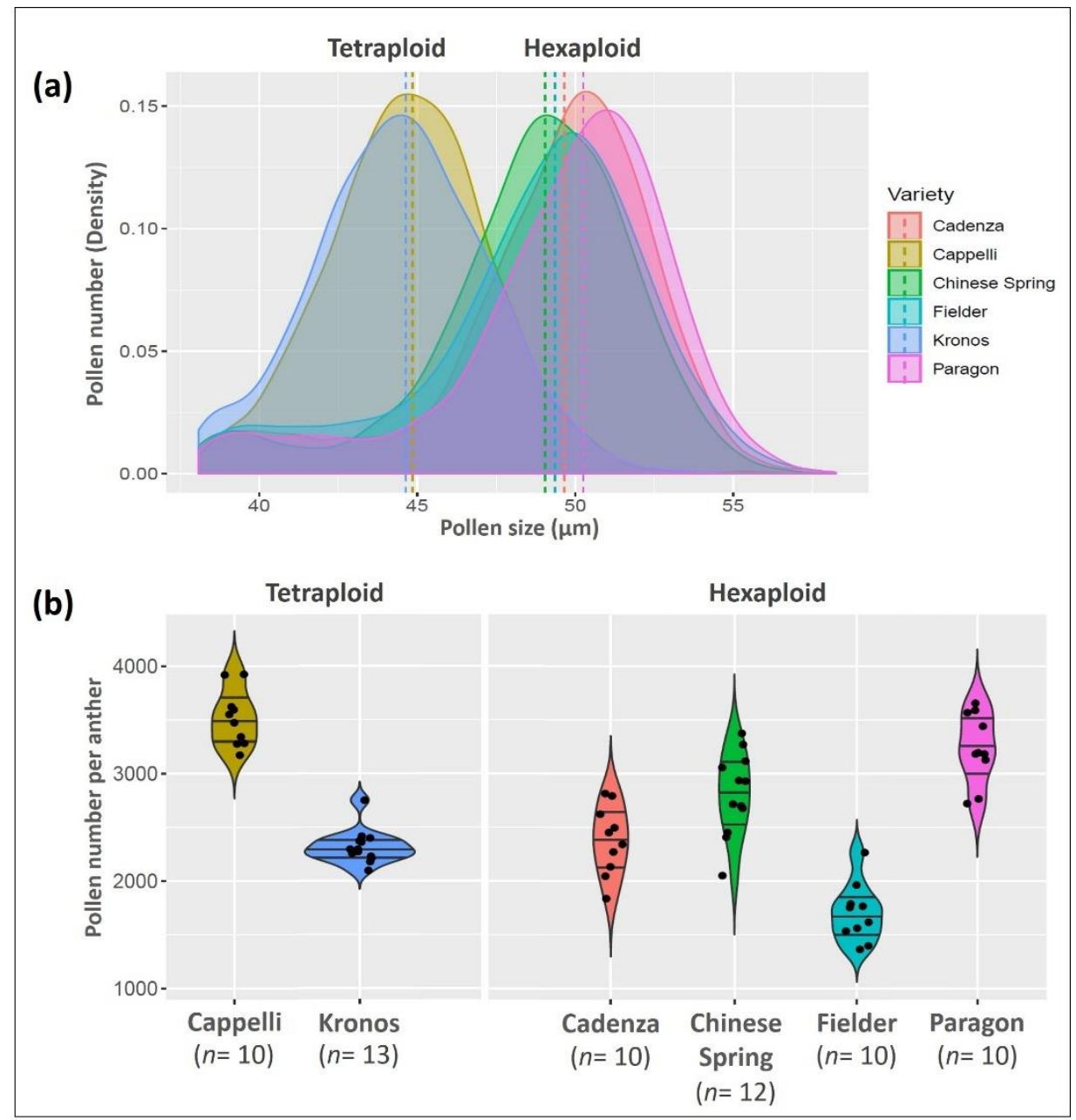

Figure 5. Pollen size and number per anther of some hexaploid and tetraploid wheats. (a) Density plot of the differential pollen size distribution data collected by coulter counter (Multisizer 4e) for four hexaploid wheats (Chinese Spring, Cadenza, Fielder and Paragon) and two tetraploid wheats (Cappelli and Kronos). Dotted lines indicate the median pollen grain size for each genotype. (b) Pollen number per anther for the six mentioned hexaploid and tetraploid wheat varieties. $n$ is number of plants (biological replicates). 
Table 3. Pollen number and pollen grain size for some hexaploid and tetraploid wheat varieties. Mean and median values with standard deviations are shown. Treatments with the same letter are not significantly different.

\begin{tabular}{lcccccc}
\hline \multirow{2}{*}{ Polyploidy } & \multirow{2}{*}{ Variety } & \multirow{2}{*}{ N } & \multicolumn{2}{c}{ Pollen Size } & \multicolumn{2}{c}{ Pollen Number Per Anther } \\
\cline { 3 - 6 } & & & Mean & Median & Mean & Median \\
\hline Hexaploid & Cadenza & 10 & $49.05 \pm 1.28^{\mathrm{a}}$ & $49.65 \pm 1.11^{\mathrm{a}}$ & $2380 \pm 320^{\mathrm{b}}$ & $2407 \pm 348^{\mathrm{b}}$ \\
Hexaploid & Chinese Spring & 12 & $48.58 \pm 1.17^{\mathrm{a}}$ & $49.05 \pm 1.15^{\mathrm{a}}$ & $2807 \pm 384^{\mathrm{c}}$ & $2840 \pm 408^{\mathrm{c}}$ \\
Hexaploid & Fielder & 10 & $48.67 \pm 0.98^{\mathrm{a}}$ & $49.36 \pm 1.19^{\mathrm{a}}$ & $1973 \pm 272^{\mathrm{a}}$ & $1686 \pm 250^{\mathrm{a}}$ \\
Hexaploid & Paragon & 10 & $49.51 \pm 1.09^{\mathrm{a}}$ & $50.25 \pm 1.22^{\mathrm{a}}$ & $3318 \pm 236^{\mathrm{d}}$ & $3293 \pm 339^{\mathrm{d}}$ \\
Tetraploid & Cappelli & 10 & $44.77 \pm 1.40^{\mathrm{b}}$ & $44.85 \pm 1.48^{\mathrm{b}}$ & $3515 \pm 260^{\mathrm{d}}$ & $3480 \pm 277^{\mathrm{d}}$ \\
Tetraploid & Kronos & 13 & $44.44 \pm 1.39^{\mathrm{b}}$ & $44.63 \pm 1.52^{\mathrm{b}}$ & $2260 \pm 110^{\mathrm{b}}$ & $2373 \pm 256^{\mathrm{b}}$ \\
\hline \multicolumn{2}{l}{ All hexaploid wheat varieties } & 4 & $48.95 \pm 0.43$ & $49.58 \pm 0.51$ & $2533 \pm 657$ & $2557 \pm 684$ \\
\multicolumn{2}{l}{ All tetraploid wheat varieties } & 2 & $44.61 \pm 0.23$ & $44.74 \pm 0.15$ & $2915 \pm 849$ & $2926 \pm 783$ \\
\hline
\end{tabular}

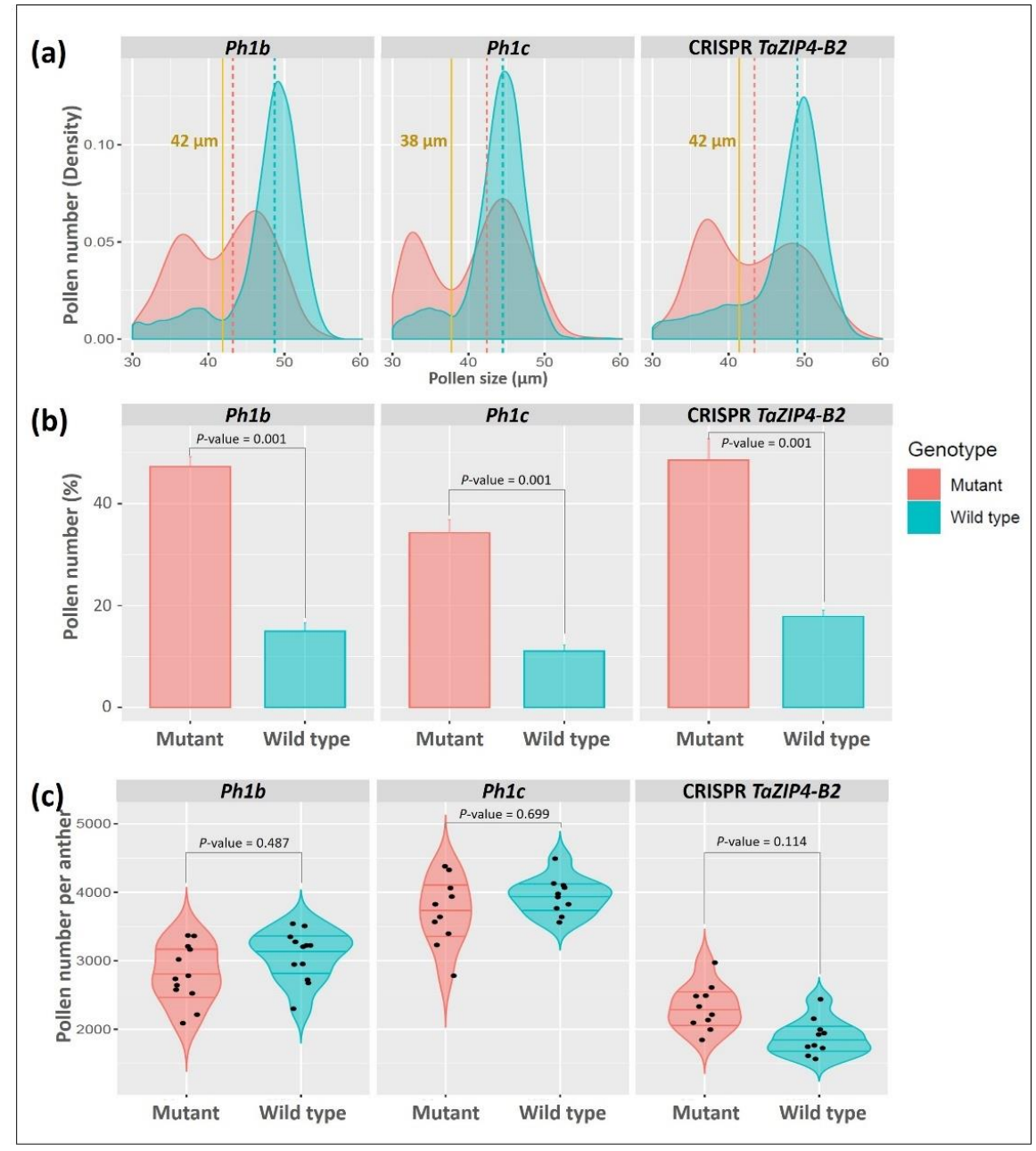

Figure 6. Pollen profiles of the three Tazip4-B2 mutants. (a) Density plot of the differential pollen size distribution data collected by coulter counter (Multisizer 4e) showing two distinguished peaks in all Tazip4-B2 mutants compared to their corresponding wild types. Dotted lines indicate the median pollen grain size for each genotype. Yellow lines indicate the borderline between normal and small pollen for each genotype group. (b) Percentages of small pollen grains for each genotype (mutants and wild types). Pollen grain is considered small when it is $\leq 42 \mu \mathrm{m}$ and $\leq 38 \mu \mathrm{m}$ for hexaploid and tetraploid wheat pollen size respectively. (c) Comparison of number of pollen grains per anther between each Tazip4-B2 mutant and its wild type. No significant difference in pollen number per anther was found between any of the mutants and its wild type. 
Table 4. Pollen number and pollen grain size for the three Tazip4-B2 mutants and their corresponding wild types. Mean and median values with standard deviations are shown. Treatments with the same letter are not significantly different.

\begin{tabular}{|c|c|c|c|c|c|c|c|c|}
\hline \multirow{2}{*}{ Genotype } & \multirow{2}{*}{$\begin{array}{l}\text { Total Number } \\
\text { of Measured } \\
\text { Pollen Grains }\end{array}$} & \multirow{2}{*}{$\mathbf{N}$} & \multicolumn{2}{|c|}{ Pollen Grain Size $(\mu \mathrm{m})$} & \multicolumn{2}{|c|}{ Pollen Number Per Anther } & \multicolumn{2}{|c|}{ Small Pollen Grains (\%) } \\
\hline & & & Mean & Median & Mean & Median & Mean & Median \\
\hline$p h 1 b$ & 10100 & 12 & $42.3 \pm 1.3^{\mathrm{a}, \mathrm{b}}$ & $43.2 \pm 1.7^{\mathrm{a}}$ & $2806 \pm 426^{a}$ & $2817 \pm 430^{a}$ & $47.2 \pm 6.9^{a}$ & $45.1 \pm 8.3^{a}$ \\
\hline cv. Chinese Spring & 11072 & 12 & $47.4 \pm 1.3^{\mathrm{c}}$ & $48.7 \pm 1.5^{b}$ & $3076 \pm 370^{\mathrm{a}}$ & $3082 \pm 364^{\mathrm{a}}$ & $15.0 \pm 5.6^{b}$ & $13.2 \pm 2.5^{b}$ \\
\hline$p h 1 c$ & 11139 & 10 & $40.9 \pm 1.9^{b}$ & $42.4 \pm 2.6^{\mathrm{a}}$ & $3713 \pm 497^{c}$ & $3681 \pm 593^{c}$ & $34.3 \pm 8.2^{c}$ & $34.4 \pm 8.3^{c}$ \\
\hline cv. Cappelli & 11840 & 10 & $43.7 \pm 1.5^{\mathrm{a}}$ & $44.5 \pm 1.5^{\mathrm{a}}$ & $3947 \pm 270^{c}$ & $3950 \pm 248^{c}$ & $11.1 \pm 3.8^{b}$ & $10.7 \pm 4.0^{\mathrm{b}}$ \\
\hline CRISPR Tazip4-B2 & 13904 & 10 & $43.1 \pm 2.1^{\mathrm{a}}$ & $43.4 \pm 3^{\mathrm{a}}$ & $2317 \pm 333^{b}$ & $2354 \pm 379^{a, b}$ & $48.5 \pm 13.4^{\mathrm{a}}$ & $48.6 \pm 13.4^{a}$ \\
\hline cv. Fielder & 11313 & 10 & $47.3 \pm 1.0^{\mathrm{c}}$ & $49.1 \pm 1.2^{b}$ & $1886 \pm 265^{b}$ & $1875 \pm 231^{b}$ & $17.9 \pm 3.9^{b}$ & $19.1 \pm 6.3^{b}$ \\
\hline
\end{tabular}

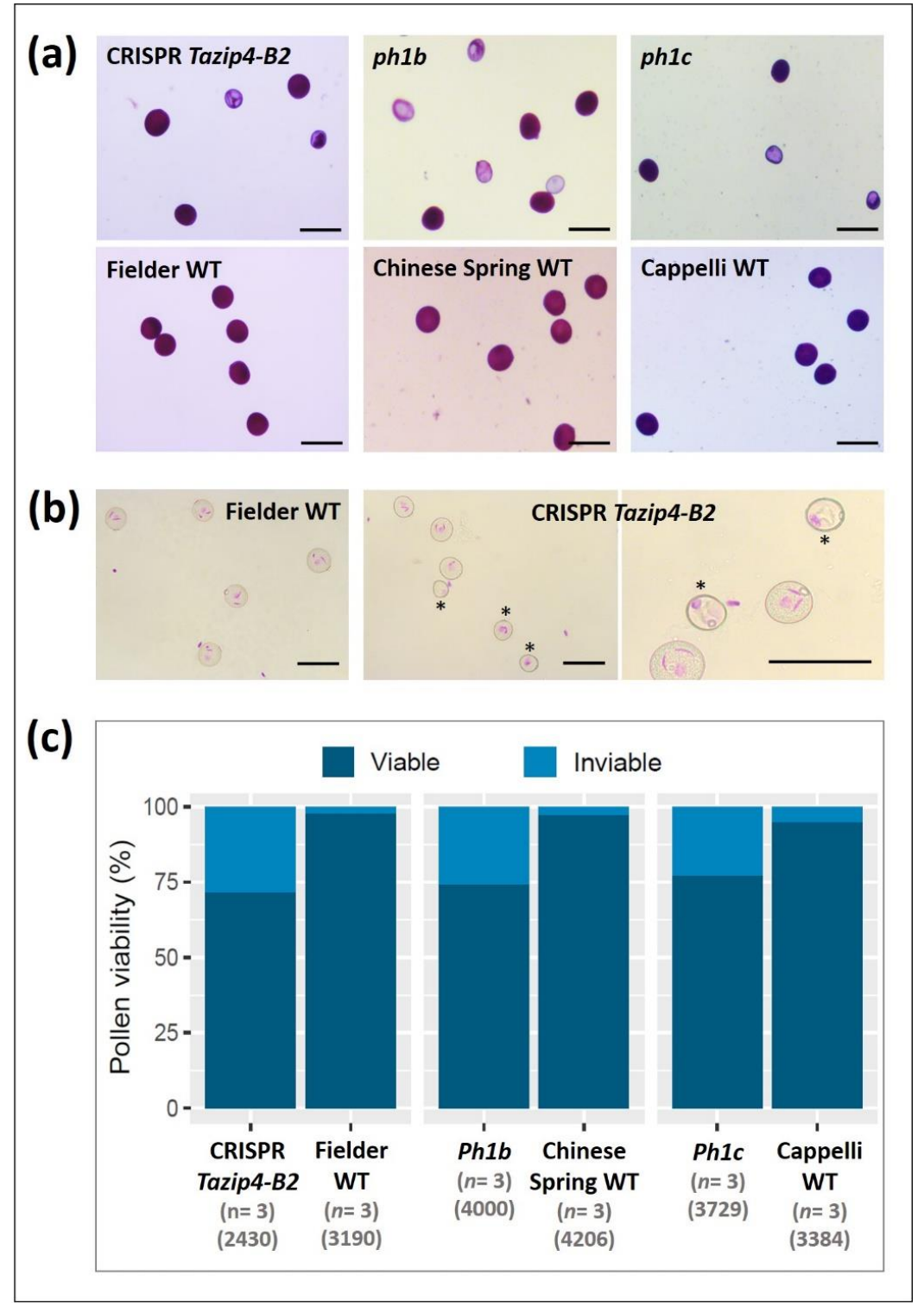

Figure 7. Pollen viability of the Tazip4-B2 mutants. (a) Pollen with magenta colour after staining with Alexander stain was considered viable, whereas blue-green pollen was considered unviable. Bars equal $100 \mu \mathrm{m}$ in length. (b) Feulgen staining of pollens from anthers at anthesis in the CRISPR Tazip4-B2 mutant and its wild type (cv. Fielder) shows normal trinucleate pollen grains in the wild type, whilst almost half of pollens were immature and/or abnormal in the mutant. Immature and abnormal pollen grains are indicated by an asterisk. Bars equal $100 \mu \mathrm{m}$ in length. (c) Percentages of viable and unviable pollens according to the Alexander staining method for the three Tazip4-B2 mutants and their wild types. $n$ refers to the number of biological replicates. Numbers between brackets refer to the total number of scored pollen grains for each genotype. 


\section{Discussion and Conclusions}

Polyploid literature highlights the requirement for a newly developed polyploid to retain production of balanced gametes to preserve fertility, through both meiotic and genomic adaptations [1-4]. However, surprisingly few of these polyploid meiotic adaptions have been characterised. Recent studies have assessed the effect of natural gene variation on the meiotic stabilisation process. For instance, at least eight different autotetraploid Arabidopsis meiotic genes have been implicated in meiotic stabilisation [47], with specific alleles in one of these genes, $A S Y 3$, being highlighted in two further studies [48,49]. Allotetraploid Brassica studies have also reported a number of loci exhibiting natural variation in their ability to affect homoeologous pairing and crossover [50-52].

In the present study, we have assessed the stabilising effects of the meiotic gene TaZIP4$B 2$, which arose on chromosome $5 \mathrm{~B}$ during wheat polyploidisation, through duplication from chromosome 3B [18-20]. Results indicate that the deletion of the duplicated TaZIP4B2 copy (through CRISPR deletion of Tazip4-B2) results in 56\% of meiocytes exhibiting meiotic abnormalities at metaphase I (Figures 2 and $3 a, b)$; chromosome mis-segregation at anaphase I (Figure 3c-f); 50\% of tetrads possessing micronuclei (Figure 3g-j); and lastly, $48 \%$ of pollen grains being small (a mixture of immature and unviable) (Figures 6 and 7). A similar level of disruption is also observed in a hexaploid mutant (ph1b) carrying a $59.3 \mathrm{Mb}$ deletion encompassing TaZIP4-B2, with 56\% of meiocytes exhibiting meiotic abnormalities (Figure 2) and $47 \%$ of pollen grains being small (Figure 6). Results suggest a direct correlation between meiotic abnormalities observed at metaphase I and pollen fertility. Importantly, there is also up to a $44 \%$ reduction in grain set in the CRISPR Tazip4-B2 mutant ( $43 \%$ reduction in the $p h 1 b$ mutant) (Figure $4 a)$. A considerable part of this reduction in grain set is likely to be due to pollination with immature/unviable pollen (Figure $4 b$ ), rather than being mainly due to disruption in female gametogenesis. Pollen deposition and pollen grain size can have an effect on pollen competition for the ovule [53,54]. However, it is still unclear how, within the 50:50 mixture of WT and immature/unviable pollen, WT pollen does not compete more effectively during pollination.

Development of in situ approaches are required to explain the observed apparently lesser effect of Tazip4-B2 on subsequent female gametogenesis. It is likely that, as in male meiocytes, meiotic abnormalities are exhibited in female meiocytes at metaphase I and MN during the tetrad stage. Study of this tetrad stage, when only a single megaspore remains [41], will identify any preferential abortion of megaspores with unbalanced chromosome numbers due to disrupted meiotic pairing and crossover. However, whatever the importance of Tazip4-B2 for female gametogenesis, the presence of TaZIP4-B2 was still required to ensure nearly half the hexaploid wheat grain set, confirming the great importance and impact of the ZIP4 duplication event on the fertility of this major global polyploid crop.

In diploids, mutation of a single copy meiotic gene is often associated with meiotic abnormality, reduced fertility or sterility. However, in polyploids, this is generally not the case, particularly in a hexaploid such as bread wheat. For example, hexaploid wheat mutants carrying single copy deletions covering the major meiotic genes DMC1, ASY1, FIG1, SPOII and MLH1, largely exhibit a wild type phenotype, when configurations are scored at metaphase I [15]. Similarly, in hexaploid wheat, all three copies of SPOII.2 require mutation to produce sterility [55], while in tetraploid wheat, both copies of MSH4 and MSH5 require mutation to produce a meiotic phenotype [56]. However, unusually, hexaploid wheat mutants with deletions covering TaZIP4-B2 in the long arm of chromosome $5 \mathrm{~B}$, did exhibit meiotic abnormalities. This occurrence of a meiotic pairing and crossover phenotype leading to reduced fertility with loss of a single copy of TaZIP4-B2 is surprising, given the presence of three other ZIP4 copies in the hexaploid wheat genome.

Recently, a study has characterised $P h 2$ in wheat as being $M S H 7-3 D$, which, in common with TaZIP4-B2, suppresses homoeologous crossover [57]. However, TaZIP4-B2 also has a major effect on chromosome pairing, by promoting homologous pairing. Interestingly, in contrast to the Tazip4-B2 mutants reported here, $m s h 7-3 D$ mutants do not exhibit a 
significant reduction in grain number and only a $20 \%$ reduction in pollen viability. This suggests that when considering preservation of pollen viability and grain number, the ability of TaZIP4-B2 to promote homologous pairing is more important than its ability to suppress homoeologous crossover. In budding yeast, ZIP4 reduces premature separation of sister chromatids at anaphase I [58]. In the present study, Tazip4-B2 deletion mutants exhibit extensive premature sister chromatid separation (Figure 3). A previously described Tazip4-B2 TILLING mutant (termed Cad1691), carrying a single amino acid change affecting both homologous and homoeologous crossover, but not homologous pairing [18] could now be exploited to confirm the link between promotion of homologous pairing and reduction of premature sister chromatid separation. Fertility scoring of this same Tazip4-B2 TILLING mutant could also confirm whether the TaZIP4-B2 homologous pairing effect is indeed more important for preservation of fertility than its effect on homoeologous crossover suppression.

In hexaploid wheat, the duplicated TaZIP4-B2 copy promotes homologous pairing, synapsis and crossover, and suppresses homoeologous crossover, so preserving pollen viability and grain set. In Arabidopsis [21] and rice [22], ZIP4 is required for $85 \%$ of homologous crossovers during meiosis, but studies have not shown a role for ZIP4 in pairing and/or synapsis. In Sordaria [59] and budding yeast [58], ZIP4 is required for pairing and synapsis, as well as homologous crossover; in Sordaria, ZIP4 foci form 'pairing bridges' between chromosomes. The hexaploid wheat TaZIP4-B2 phenotypes most likely result from a reduction in the normal functions of group $3 \mathrm{ZIP} 4 \mathrm{~s}$, as a consequence of the TPR divergence within TaZIP4-B2 from that within TaZIP4-B1 (Figure 1b,c). The early and 3-fold increased expression of TaZIP4-B2 compared to the group 3 ZIP4s, is also likely to ensure that it competes with them for loading onto meiotic chromosomes [18]. The present study reveals that up to half the wheat ZIP4 protein is composed of TPRs (Figure $1 b, c)$. The presence of TPRs in other proteins has been shown to enable these proteins to form alpha solenoid helix structures capable of assembling protein complexes [34,35]. Recent studies in budding yeast have revealed that ZIP4 interacts with axis and crossover proteins, which may provide the basis of its effects in wheat [60]. Previous studies have suggested that the ph1b deletion effect on homoeologous crossover in wheat is linked to the improved ability of the meiotic crossover protein MLH1 to process crossovers [38], while the $p h 1 b$ deletion effect on chromosome pairing reported by Roberts et al. [15] is linked to the chromosome axis protein, ASY1 [61]. Recent studies in budding yeast have revealed that ZIP4 is connected to MLH1 through the binding to MER3, to HOP1 (ASY1) through the binding of another chromosome axis protein RED1 (ASY3), and to synapsis proteins through ZIP2 [60].

The promotion of homologous pairing by TaZIP4-B2 is likely to be related to the elongation of the chromosome axis on entry into meiosis [62], and the association of ZIP4 foci on these axes forming 'pairing bridges' between homologues [59]. If the extent of homologue elongation is different, then homologue alignment and pairing is delayed during early meiosis [63]. REC8, a cohesion protein, is required for correct meiotic chromosome conformation, and chromosome axis elongation via assembly of ASY1 [64,65]. ZIP4 locates at the end of REC8-associated chromatin regions [22]. Thus, the simplest explanation for the ability of TaZIP4-B2 to promote homologous pairing is that TaZIP4-B2 reduces homologue elongation, ensuring more similar conformations and allowing rapid association of ZIP4 foci, so reducing the chance of homoeologous pairing which occurs later in meiosis $[28,38,62]$.

The suppression of homoeologous crossover by TaZIP4-B2 is likely to result from the interplay between this chromosome 5B copy and the three group 3 chromosome ZIP4 copies. The group 3 ZIP4s are likely to process $85 \%$ of homologous crossovers as in other species [21,22]. They are also likely to process homoeologous crossover activity, given the level of crossover observed in wheat haploids lacking TaZIP4-B2 [66]. In contrast, although the diverged TaZIP4-B2 copy has some homologous crossover activity, it does not possess any homoeologous crossover activity [19]. Sordaria studies reveal that initial chromosome 
interactions involve ZIP4 foci on homologous chromosomes [59]. Thus, the presence of TaZIP4-B2 with wheat group 3 ZIP4s in chromosome foci which assemble crossover proteins including MLH1, means that only homologous crossovers are successfully processed rather than homoeologous crossovers $[14,19,38]$.

Deletion of TaZIP4-B2 reduces homologous crossover, contributing to an increase in meiotic abnormalities at metaphase I (Figure 2) [19]. This suggests that the presence of TaZIP4-B2 increases homologous crossover, indicating that the ZIP4 effect on homologous crossover may be dosage dependent. This contrasts with other meiotic genes analysed in polyploid Brassica and wheat, where loss of a single gene copy does not reduce overall homologous crossover, with homologous crossover only being affected if all gene copies are deleted $[56,67]$. This also highlights that the significant reduction in polyploid fertility with the loss of one of the gene copies (in this case, TaZIP4-B2), may be unusual for meiotic genes in polyploids. Thus, ZIP4 was an effective target for divergence on polyploidisation, as its homologous crossover activity appears to be dosage dependent.

Given the importance of the TaZIP4-B2 function for preserving grain number in wheat, future studies will need to confirm that the phenotype of TaZIP4-B2 results from a reduction in the function activities possessed by the group 3 ZIP4s. Such studies will also need to confirm whether different TaZIP4 B2 alleles exhibit variable phenotypes sensitive to temperature change. Natural variation in meiotic phenotypes has been reported for some meiotic genes in other polyploids [47-52]. The approach for analysing pollen presented in this study can be used in future TaZIP4-B2 studies to screen landrace diversity mapping populations [68], carrying different TaZIP4-B2 alleles for variable phenotypes, with variable sensitivity to temperature. This approach is high throughput and sensitive, with the capability to screen 1000s of pollen grains rapidly. Thus, the approach can be used for forward and reverse meiotic genetic screening. The approach has already been successfully used in a forward genetics screen to identify temperature sensitive mutants in hexaploid wheat (unpublished). In the present study, the technique was used to analyse pollen derived from both tetraploid and hexaploid meiotic mutants, revealing the presence of small pollen (Figure $6 \mathrm{a}, \mathrm{b}$ ). The recent availability of multiple sequenced wheat genomes has allowed the initial identification of haplotype blocks [68], revealing different TaZIP4$B 2$ haplotypes. This information, combined with the availability of landrace diversity mapping populations [69] and the pollen technique, can be used to rapidly identify any potential natural phenotype variation correlating with a specific TaZIP4-B2 haplotype, as well as to explore the stability of such phenotypes under variable temperatures. This will be important for studies exploring the effects of temperature increases on wheat yields within the context of global climate change.

Supplementary Materials: The following are available online at https://www.mdpi.com/article/ 10.3390/biology10040290/s1: Table S1: TPR and domain prediction in TaZIP4 proteins. Table S2: Summary of the meiotic scores. Table S3: Grain number per spike. Table S4: Male_Female sterility. Table S5: Seed germination experiment. Table S6: Pollen size_pollen number_WTs. Table S7: Pollen size_Pollens number_small pollen_TaZIP4. Table S8: Pollen viability scores. Text S1: The used R scripts. Figure S1: Pollen profiles and storage times.

Author Contributions: A.K.A. developed the pollen analysis and applied it to study the Tazip4-B2 mutants. A.K.A. undertook the grain set experiment; emasculation/pollination experiment, and their analysis, producing the figures and tables for all these data. A.C.M. carried out the cytological and immunolocalisation experiments and produced the immunolocalisation figure. G.M. carried out the TaZIP4 protein analysis, and A.K.A. the sequence alignments producing the resulting figure. G.M. provided thoughts and guidance and revised and edited the manuscript produced by A.K.A. and A.C.M. All authors have read and agreed to the published version of the manuscript.

Funding: This research was funded by UKRI-Biological and Biotechnology Research Council (BBSRC), grant numbers BB/P016855/1 and BB/R0077233/1.

Institutional Review Board Statement: Not Applicable.

Informed Consent Statement: Not Applicable. 
Data Availability Statement: Datasets supporting the findings of this study are available in the Supplementary Materials of this article and from the corresponding author upon reasonable request.

Acknowledgments: The authors would like to thank David Seung for his helpful discussions and advice with regard to the analysis of the pollen measurement data. This work was supported by the UKRI-Biological and Biotechnology Research Council (BBSRC) through a grant as part of the 'Designing Future Wheat' (DFW) Institute Strategic Programme (BB/P016855/1) and Response Mode Grant (BB/R0077233/1).

Conflicts of Interest: The authors declare no conflict of interest.

\section{References}

1. Comai, L. The advantages and disadvantages of being polyploid. Nat. Rev. Genet. 2005, 6, 838-846. [CrossRef]

2. Otto, S.P. The evolutionary consequences of polyploidy. Cell 2007, 131, 452-462. [CrossRef] [PubMed]

3. Pelé, A.; Rousseau-Gueutin, M.; Chevre, A.-M. Speciation Success of polyploid plants closely relates to regulation of meiotic recombination. Front. Plant Sci. 2018, 9, 907. [CrossRef] [PubMed]

4. Feliner, G.N.; Casacuberta, J.; Wendel, J.C. Genomics of Evolutionary Novelty in Hybrids and Polyploids. Front. Genet. 2020, 11, 792. [CrossRef]

5. $\quad$ Osborn, T.C.; Pires, J.C.; Birchler, J.A.; Donald, L.; Auger, D.L.; Chen, Z.J.; Lee, H.-S.; Comai, L.; Madlung, A.; Doerge, R.W.; et al. Understanding mechanisms of novel gene expression in polyploids. Trends Genet. 2003, 19, 141-147. [CrossRef]

6. Adams, K.L.; Wendel, J.F. Novel patterns of gene expression in polyploid plants. Trends Gen. 2005, 21, 539-543. [CrossRef]

7. Mason, A.S.; Wendel, J.F. Homoeologous exchanges, segmental allopolyploidy, and polyploid genome evolution. Front. Genet. 2020, 11, 1014. [CrossRef]

8. Ramírez-González, R.H.; Borrill, P.; Lang, D.; Harrington, S.A.; Brinton, J.; Venturini, L.; Davey, M.; Jacobs, J.; van Ex, F.; Pasha, A.; et al. The transcriptional landscape of polyploid wheat. Science 2018, 361, e6089. [CrossRef]

9. Alabdullah, A.K.; Borrill, P.; Martin, A.C.; Ramirez-Gonzalez, R.H.; Uauy, C.; Shaw, P.; Moore, G. A co-expression network in hexaploid wheat reveals mostly balanced expression and lack of significant gene loss of homeologous meiotic genes upon polyploidization. Front. Plant Sci. 2019, 10, 1325. [CrossRef]

10. Riley, R.; Chapman, V. Genetic control of the cytological diploid behaviour of hexaploid wheat. Nature 1958, 182, 713-715. [CrossRef]

11. Sears, E.R.; Okamoto, M. Intergenomic chromosome relationships in hexaploid wheat. Theor. Appl. Genet. 1991, 82, 441-449.

12. Wall, A.M.; Riley, R.; Gale, M.D. The position of a locus of chromosome 5B in Triticum aestivum affecting homoeologous meiotic pairing. Genet. Res. 1971, 18, 329-339. [CrossRef]

13. Sears, E.R. Induced mutant with homoeologous pairing in common wheat. Can. J. Genet. Cytol. 1977, 19, 585-593. [CrossRef]

14. Martín, A.C.; Borrill, P.; Higgins, J.; Alabdullah, A.K.; Ramírez-González, R.H.; Swarbeck, D.; Uauy, C.; Shaw, P.; Moore, G. Overall wheat transcription during early meiosis is independent of synapsis, ploidy level and the Ph1 locus. Front. Plant Sci. 2018, 9, 1791. [CrossRef]

15. Roberts, M.A.; Reader, S.; Dalgliesh, C.; Miller, T.; Foote, T.; Fish, L.J.; Snape, J.W.; Moore, G. Induction and characterization of Ph1 wheat mutants. Genetics 1999, 153, 1909-1918.

16. Griffiths, S.; Sharp, R.; Foote, T.N.; Bertin, I.; Wanous, M.; Reader, S.; Colas, I.; Moore, G. Molecular characterization of Ph1 as a major chromosome pairing locus in polyploid wheat. Nature 2006, 439, 749-752. [CrossRef]

17. Al-Kaff, N.; Knight, E.; Bertin, I.; Foote, T.; Hart, N.; Griffiths, S.; Moore, G. Detailed dissection of the chromosomal region containing the Ph1 locus in wheat Triticum aestivum: With deletion mutants and expression profiling. Annu. Bot. 2008, 105, 863-872. [CrossRef]

18. Rey, M.-D.; Martín, A.C.; Higgins, J.; Swarbreck, D.; Uauy, C.; Shaw, P.; Moore, G. Exploiting the ZIP4 homologue within the wheat $\mathrm{Ph} 1$ locus has identified two lines exhibiting homoeologous crossover in wheat-wild relative hybrids. Mol. Breed. 2017, 37, 95. [CrossRef]

19. Rey, M.-D.; Martín, A.C.; Smedley, M.; Hayta, S.; Harwood, W.; Shaw, P.; Moore, G. Magnesium increases homoeologous crossover frequency during meiosis in Tazip4-B2 (Ph1 gene) mutant wheat-wild relative hybrids. Front. Plant Sci. 2018, 9, 509. [CrossRef]

20. International Wheat Genome Sequencing Consortium (IWGSC). Shifting the limiting in wheat research and breeding using a fully annotated reference genome. Science 2018, 362, eaar7191.

21. Chelysheva, L.; Gendrot, G.; Vezon, D.; Doutriaux, M.-P.; Mercier, R.; Grelon, M. Zip4/Spo22 is required for class I CO formation but not for synapsis completion in Arabidopsis thaliana. PLoS Genet. 2007, 3, e83. [CrossRef] [PubMed]

22. Shen, Y.; Wang, T.K.; Wang, W.; Huang, J.; Luo, W.; Luo, Q.; Hong, L.H.; Li, M.; Cheng, Z. ZIP4 in homologous chromosome synapsis and crossover formation in rice meiosis. J. Cell Sci. 2012, 125, 2581-2591. [CrossRef]

23. Pagliarini, M.S. Meiotic behavior of economically important plant species: The relationship between fertility and male sterility. Genet. Mol. Biol. 2000, 23, 997-1002. [CrossRef]

24. Sheidai, M.; Jafari, S.; Taleban, P.; Keshavarzi, M. Cytomixis and unreduced pollen grain formation in Alopecurus L. and Catbrosa Beauv. (Poaceae). Cytologia 2009, 74, 31-41. [CrossRef] 
25. Sheidai, M.; Jafari, S.; Nourmohammadi, Z.; Beheshti, S. Cytomixis and unreduced pollen grain formation in six Hordeum species. Gene Conserve. 2010, 9, 40-50.

26. Giorgi, B. Origin, behaviour and utilization of a Ph1 mutant of durum wheat, Triticum turgidum (L.) var. durum. In Proceedings of the 6th International Wheat Genetetics Symposium, Kyoto, Japan, 28 November-3 December 1983; pp. 1033-1040.

27. Alexander, M.P. Differential staining of aborted and nonaborted pollen. Stain Technol. 1969, 44, 117-122. [CrossRef]

28. Martín, A.C.; Rey, M.-D.; Shaw, P.; Moore, G. Dual effect of the wheat Ph1 locus on chromosome synapsis and crossover. Chromosoma 2017, 126, 669-680. [CrossRef]

29. Sharma, A.K.; Sharma, A. Chromosome Techniques: Theory and Practice; Butterworth-Heinemann: Oxford, UK, 2014.

30. Rey, M.D.; Moore, G.; Martín, A.C. Identification and comparison of individual chromosomes of three accessions of Hordeum chilense, Hordeum vulgare, and Triticum aestivum by FISH. Genome 2018, 61, 387-396. [CrossRef]

31. Higgins, D.G.; Sharp, P.M. CLUSTAL: A package for performing multiple sequence alignment on a microcomputer. Gene 1988, 73, 237-244. [CrossRef]

32. Larkin, M.A.; Blackshields, G.; Brown, N.P.; Chenna, R.; McGettigan, P.A.; McWilliam, H.; Valentin, F.; Wallace, I.M.; Wilm, A.; Lopez, R.; et al. Clustal W and Clustal $X$ version 2.0. Bioinformatics 2007, 23, 2947-2948. [CrossRef]

33. Mitchell, A.L.; Attwood, T.K.; Babbitt, P.C.; Blum, M.; Bork, P.; Bridge, A.; Brown, S.D.; Chang, H.-Y.; El-Gebali, S.; Fraser, M.I.; et al. InterPro: Improving coverage.; classification and access to protein sequence annotations. Nucleic Acids Res. 2019, 47, D351-D360. [CrossRef]

34. Blatch, G.L.; Lassle, M. The tetratricopeptide repeat: A structural motif mediating protein-protein interactions. Bioessays 1999, 21, 932-939. [CrossRef]

35. D'Andrea, L.D.; Regan, L. TPR proteins: The versatile helix. Trends Biochem. Sci. 2003, 28, 655-662. [CrossRef]

36. Zimmermann, L.; Stephens, A.; Nam, S.Z.; Rau, D.; Kübler, J.; Lozajic, M.; Gabler, F.; Söding, J.; Lupas, A.N.; Alva, V. A completely reimplemented MPI bioinformatics toolkit with a new HHpred server at its core. J. Mol. Biol. 2018, 430, 2237-2243. [CrossRef] [PubMed]

37. Delorenzi, M.; Speed, T. An HMM model for coiled-coil domains and a comparison with PSSM-based predictions. Bioinformatics 2002, 18, 617-625. [CrossRef] [PubMed]

38. Martín, A.C.; Shaw, P.; Phillips, D.; Reader, S.; Moore, G. Licensing MLH1 sites for crossover during meiosis. Nat. Commun. 2014, 5, 1-5. [CrossRef] [PubMed]

39. Zhang, P.; Li, W.; Fellers, J.; Friebe, B.; Gill, B.S. BAC-FISH in wheat identifies chromosome landmarks consisting of different types of transposable elements. Chromosoma 2004, 112, 288-299. [CrossRef]

40. Gerlach, W.L.; Bedbrook, J.R. Cloning and charcacterisation of ribosomal RNA genes from wheat and barley. Nucleic Acids Res. 1979, 11, 1869-1885. [CrossRef]

41. Morrison, J.W. Chromosome behaviour in wheat monosomics. Heredity 1953, 7, 203-217. [CrossRef]

42. Lamborn, E.; Cresswell, J.E.; Macnair, M.R. The potential for adaptive evolution of pollen grain size in Mimulus guttatus. New Phytol. 2005, 16, 289-296. [CrossRef] [PubMed]

43. De Storme, N.; Zamariola, L.; Mau, M.; Sharbel, T.F.; Geelen, D. Volume-based pollen size analysis: An advanced method to assess somatic and gametophytic ploidy in flowering plants. Plant Reprod. 2013, 26, 65-81. [CrossRef] [PubMed]

44. Cetl, I. The size of pollen grain of the genus Triticum L. Biol. Plantarum 1960, 2, 287-291. [CrossRef]

45. Saps. Pollen Images in Size Order. Available online: https://saps.org.uk/pollen/index2.htm (accessed on 20 January 2021).

46. De Vries, A. Some aspects of cross-pollination in wheat (Triticum aestivum L.). 3. Anther length and number of pollen grains per anther. Euphytica 1974, 23, 11-19. [CrossRef]

47. Yant, Y.; Hollister, J.D.; Wright, K.M.; Arnold, B.J.; Higgins, J.D.; Franklin, F.C.H.; Bomblies, K. Meiotic adaption to genome duplication in Arabidopsis arenosa. Curr. Biol. 2013, 23, 2151-2156. [CrossRef]

48. Morgan, C.; Zhang, H.; Henry, C.E.; Franklin, C.F.H.; Bomblies, K. Derived alleles of two axis proteins affect meiotic traits in autotetraploid Arabidopsis arenosa. Proc. Natl. Acad. Sci. USA 2020, 117, 8980-8988. [CrossRef]

49. Seear, P.J.; France, M.J.; Gregory, C.L.; Heavens, D.; Schmickl, R.; Yant, L.; Higgins, J.D. A novel allele of ASY3 is associated with greater meiotic stability in autotetraploid Arabidopsis lyrata. PLoS Genet. 2020, 16, e1008900. [CrossRef]

50. Jenczewski, E.; Eber, F.; Grimaud, A.; Huet, S.; Lucas, M.O.; Monod, H.; Chevre, A.M. PrBn, a major gene controlling homeologous pairing in oilseed rape (Brassica napus) haploids. Genetics 2003, 164, 645-653.

51. Liu, Z.; Adamczyk, K.; Manzanares-Dauleux, M.; Eber, F.; Lucas, M.O.; Delourme, R.; Chevre, A.M.; Jenczewski, E. Mapping $\mathrm{PrBn}$ and other quantitative trait loci responsible for the control of homeologous chromosome pairing in oilseed rape (Brassica napus L.) haploids. Genetics 2006, 174, 1583-1596. [CrossRef]

52. Higgins, E.E.; Howell, E.C.; Armstrong, S.J.; Parkin, I.A.P. A major quantitative trait locus on chromosome A9, BnaPh1 controls homoeologous recombination in Brassica napus. New Phytol. 2020, 229, 3041-3043.

53. Cruden, R.W.; Miller-Ward, S. Pollen-ovule ratio, pollen size, and the ratio of stigmatic area to the pollen-bearing area of the pollinator: An hypothesis. Evolution 1981, 35, 964-974. [CrossRef] [PubMed]

54. Németh, M.B.; Smith-Huerta, N.L. Pollen deposition, pollen tube growth, seed production, and seedling performance in natural populations of Clarkia Unguiculata (Onagraceae). Int. J. Plant Sci. 2003, 164, 153-164. [CrossRef]

55. Benjahya, F.; Naduad, I.; Da Innes, O.; Rimbert, H.; White, C.; Sourdille, P. SPOII.2 is essential for programmes double strand break formation during meiosis in bread wheat (Triticum aestivum L.). Plant J. 2020, 104, 30-43. [CrossRef] 
56. Desjardins, S.D.; Ogle, D.E.; Ayoub, M.A.; Heckman, S.; Henderson, I.R.; Edwards, K.J.; Higgins, J.D. MutS homologue 4 and MutS homologue 5 maintain the obligate crossover despite stepwise gene loss following polyploidisation. Plant Physiol. 2020, 183, 1545-1558. [CrossRef]

57. Serra, H.; Svačina, R.; Baumann, U.; Whitford, R.; Sutton, T.; Bartoš, J.; Sourdille, P. Ph2 encodes the mismatch repair protein MSH7-3D that inhibits wheat homoeologous recombination. Nat. Commun. 2021, 12, 801. [CrossRef]

58. Tsubouchi, T.; Zhao, H.; Roeder, G.S. The meiosis-specific ZIP4 protein regulates crossover distribution by promoting synaptonemal complex formation together with ZIP2. Dev. Cell 2006, 10, 809-819. [CrossRef]

59. Dubois, E.; Muyt, A.D.; Soyer, J.L.; Budin, K.; Legras, M.; Piolot, T.; Debuchy, R.; Kleckner, N.; Zickler, D.; Espagne, E. Building bridges to move recombination complexes. Proc. Natl. Acad. Sci. USA 2019, 116, 12400-12409. [CrossRef]

60. Pyatnitskaya, A.; Borde, V.; Muyt, A.D. Crossing and zipping: Molecular duties of ZMM proteins in meiosis. Chromosoma 2019, 128, 181-198. [CrossRef]

61. Boden, S.A.; Langridge, P.; Spangenberg, G.; Able, J. TaASY1 promotes homologous chromosome interactions and is affected by deletion of Ph1. Plant J. 2009, 57, 487-497. [CrossRef]

62. Prieto, P.; Shaw, P.; Moore, G. Homologue recognition is associated with a change in chromatin conformation. Nat. Cell Biol. 2004, 6, 906-908. [CrossRef]

63. Colas, I.; Shaw, P.; Prieto, P.; Wanous, M.; Spielmeyer, W.; Mago, R.; Moore, G. Effective chromosome pairing requires chromatin remodeling at the onset of meiosis. Proc. Natl. Acad. Sci. USA 2008, 105, 6075-6080. [CrossRef]

64. Golubovskaya, I.N.; Hamant, O.; Timofejeva, L.; Wang, C.-J.R.; Braun, D.; Meeley, R.; Cande, Z.W. Alleles of afd1 dissect REC8 functions during meiotic prophase I. J. Cell Sci. 2006, 119, 3306-3315. [CrossRef] [PubMed]

65. Ding, D.-Q.; Matsuda, A.; Okamasa, K.; Nagahama, Y.; Haraguchi, T.; Hiraoka, Y. Meiotic cohesion-based chromosome structure is essential for homologous pairing in Schizosaccharomyces pombe. Chromosoma 2016, 125, 205-214. [CrossRef] [PubMed]

66. Jauhar, P.P.; Almousiem, A.B.; Peterson, T.S.; Joppa, L.R. Inter- and intragenomic chromosome pairing in Haploids of Durum wheat. J. Hered. 1999, 90, 437-445. [CrossRef]

67. Gonzalo, A.; Lucas, M.-O.; Charpentier, C.; Sandmann, G.; Lloyd, A.; Jenczewski, E. Reducing MSH4 copy number prevents meiotic crossovers between non-homologous chromosomes in Brassica napus. Nat. Commun. 2019, 10, 2354. [CrossRef] [PubMed]

68. Brinton, J.; Ramirez-Gonzalez, R.H.; Simmonds, J.; Wingen, L.; Orford, S.; Griffiths, S.; 10 Wheat Genome Project; Haberer, G.; Spannagl, M.; Walkowiak, S.; et al. Haplotype-led approach to increase the precision of wheat breeding. Commun. Biol. 2020, 3, 712. [CrossRef]

69. Wingen, L.U.; West, C.; Leverington-Waite, M.; Collier, S.; Orford, S.; Goram, R.; Yang, C.-Y.; King, J.; Allen, A.M.; Burridge, A.; et al. Wheat landrace genome diversity. Genetics 2017, 205, 1657-1676. [CrossRef] 